\title{
Urban Data Dynamics: A Systematic Benchmarking Framework to Integrate Crowdsourcing and Smart Cities' Standardization
}

\author{
Vaia Moustaka ${ }^{1, *(\mathbb{D}}$, Antonios Maitis ${ }^{1}\left(\mathbb{D}\right.$, Athena Vakali ${ }^{1}$ and Leonidas G. Anthopoulos ${ }^{2}$ \\ 1 Department of Informatics, Aristotle University of Thessaloniki, 54124 Thessaloniki, Greece; \\ antonismaitis@gmail.com (A.M.); avakali@csd.auth.gr (A.V.) \\ 2 Department of Business Administration, University of Thessaly, 41110 Larissa, Greece; lanthopo@uth.gr \\ * Correspondence: vmoustag@csd.auth.gr
}

Citation: Moustaka, V.; Maitis, A.; Vakali, A.; Anthopoulos, L.G. Urban Data Dynamics: A Systematic Benchmarking Framework to Integrate Crowdsourcing and Smart Cities' Standardization. Sustainability 2021, 13, 8553. https://doi.org/ $10.3390 /$ su13158553

Academic Editor: Jorge Rocha

Received: 27 June 2021

Accepted: 26 July 2021

Published: 31 July 2021

Publisher's Note: MDPI stays neutral with regard to jurisdictional claims in published maps and institutional affiliations.

Copyright: (c) 2021 by the authors. Licensee MDPI, Basel, Switzerland. This article is an open access article distributed under the terms and conditions of the Creative Commons Attribution (CC BY) license (https:// creativecommons.org/licenses/by/ $4.0 /)$.

\begin{abstract}
Urbanization and knowledge economy have highly marked the new millennium. Urbanization brings new challenges which can be addressed by the knowledge economy, which opens up scientific and technical innovation opportunities. The enhancement of cities' intelligence has heavily impacted city transformation and sustainable decision-making based on urban data knowledge extraction. This work is motivated by the strong demand for robust standardization efforts to steer and measure city performance and dynamics, given the growing tendency of conventional cities' transformation into smart and resilient ones. This paper revises the earlier so-called "cityDNA" framework, which was designed to detect the interrelations between the six smart city dimensions, such that a city's profile and capacities are recognized in a systematic manner. The updated framework implements the widely accepted smart city (ISO 37120:2018) standard, along with an adaptive Web service, which processes urban data and visualizes the city's profile to facilitate decision-making. The proposed framework offers a solid benchmarking service, at which the value of crowdsourced data is exploited for the production of urban knowledge and city transformation empowerment. The proposed benchmarking approach is tested and validated through relevant case studies and a proof-of-concept scenario, in which open data and crowdsourced data are exploited. The outcomes revealed that cities should intensify their KPI-driven data production and exploitation along with a set of solid standards for cities to enable cities with customizable scenarios enriched with indicators that reflect each city's vibrancy.
\end{abstract}

Keywords: cityDNA; smart cities; crowdsourcing; ISO 37120:2018; city profile

\section{Introduction}

The high urbanization that strongly characterizes the new millennium urges cities to address economic, environmental and social challenges at a local level, and obliged policymakers to define goals and design long-term strategies in their attempt to achieve urban sustainability. As part of tackling these challenges, the establishment of Smart and Sustainable Cities (SSC) was identified by the United Nations Development Program (https: / / www.undp.org/content/undp/en/home/about-us.html (accessed on 28 December 2020)) as one of the Sustainable Development Goals (SDGs) to be fulfilled by 2030. SSC, which focus on the transformation of conventional cities and their processes into resilient and smart, deal with interdisciplinary challenges that engage different scientific fields, since they progress with the developments at architectural, modeling, design and implementation levels [1-5]. The achievement of this goal attracted the interest of several scholars and practitioners, who proposed various solutions, both specific (e.g., for a specific city, problem, need, etc.) and generic (e.g., multipurpose services, architectures, etc.), based on their research interests and their expertise. A systematic review on smart cities (SC) revealed that the majority of services, which were designed and developed until 2017, focused mainly on the dimensions of mobility and environment compared to the rest (economy, governance and living), which appear to require citizen engagement [4]. 
More recent studies view SSC as a service-oriented environment, where smart services, such as smart health, smart energy, smart food, etc. [6,7], are being deployed between producers, consumers and prosumers (i.e., those who consume and produce), while the interest of several scholars has turned to studying and addressing social and ethical issues that emerged in cities, such as behavior analysis, security and privacy, etc. [8-10]. As it turns out, the solutions that were designed and proposed to achieve city transformation concern the entire city ecosystem and are determined by the demands of each city.

As the SSC field grows, standardization bodies seek to homogenize solutions and clearly define SSC standards to assist policymakers to plan the cities of tomorrow and to measure the results of their interventions. In the context of standardization, several international and European standardization organizations, such as ITU (http:/ / www.it u.int/en/ITU--T/focusgroups/ssc/Pages/default.aspx (accessed on 19 January 2020)), ISO (https: / / www.en-standard.eu/iso-standards / (accessed on 19 January 2020)), CEN (https://www.cen.eu/Pages/default.aspx (accessed on 19 January 2020)), CENELEC (https: / / www.cenelec.eu/ (accessed on 19 January 2020)), etc., attempted to define and propose standards and Key Performance Indicators (KPIs) to measure city performance in terms of achieving smartness, resilience and sustainability. According to [11], city performance is the capacity of a city program to create and disseminate public value. A comparative analysis of standardized indicators for SSC was conducted in [12], where it was argued that the collection of data to measure all these indicators is particularly hard and the selection of the most important ones is mainly determined by the purpose of their use. In this regard, some scholars and companies designed and proposed frameworks and tools to assist in selecting KPIs and measuring city performance. A KPI-driven performance measurement system for SC by utilizing city open data was developed in [13], while [14] presented a performance dashboard for municipalities' benchmarking and suggested ways in which a SC can use ICT-derived data to improve the benchmarking process. Additionally, TM Forum (https://www.tmforum.org/ (accessed on 19 January 2020)) launched the SC Benchmark, an application based on BSI (https: / /www.bsigroup.com/ (accessed on 19 January 2020)) aiming to enable city managers to find and share information and best practice between cities [15], while a few scholars developed ontologies and dashboards in an attempt to identify and visualize the indicators proposed by standardization bodies [16-20]. Specifically, Reference [18] proposed a context-aware and energy-efficient IoT/big data/cloud platform based on ISO 37120:2014 [21] that allows city planning and forecasting, while specific ontologies for each of the indicator themes of ISO 37120:2014 [21], such as: Education, Shelter, Health, Transport and Innovation, were proposed in $[16,17,20]$. On the other hand, SC vendors developed several platforms that depict the performance of their own KPIs, which introduced another area for standardization (https://www.itu.int/en/ITU-T/ssc/united/Pages/default.aspx (accessed on 19 January 2020)). Based on the above, up to now, the many standardization efforts evolve in a fragmented and isolated manner, since most of them focus on the effect of individual indicators in city performance, and they are not adaptive to each city's profile.

An essential prerequisite for the synthesis of the above-mentioned KPIs is the existence and availability of urban data, i.e., produced in the city's operation context [13]. This data, which is generated daily by multiple data sources, such as the Internet of Things (IoT), crowdsourcing activities, Web/mobile applications, GIS, statistical services, private and public organizations, etc., contains valuable information about city vibrancy, and the amount produced depends on the urban policy and infrastructure of each city [4]. However, a small amount of this data is made available to the public through open data platforms developed by municipalities, and this data is usually archival data that is published on a monthly, quarterly or annual basis $[13,18]$. Although open data platforms are increasing, the exploitation of open data for the synthesis of indicators encounters fundamental barriers. The origin of the data, the rate and duration of data collection, their relevance to performance metrics, their processing methods, metadata, etc., are factors that need to be taken into account by municipalities when designing their open data platforms 
so that the synthesis of indicators from open data is feasible [16-18,20]. In this context, the ISO/IEC 30182:2017 Standard was developed, which sets out the requirements that need to be met by urban data in order to be used for the synthesis of indicators and the acquisition of knowledge in cities. Additionally, the World Council on City Data (WWCD (https:/ / www.dataforcities.org/ (accessed on 19 January 2020))), which implements the ISO 37120:2018 Standard (Sustainable cities and communities-Indicators for city services and quality of life) [22] that proposes indicators for city services and quality, attempts to help cities to standardize the data they publish on their open data platforms. ISO 37120:2018 is the most widely accepted standard for cities, since it constitutes the first standard to be developed as part of a comprehensive set of standards for sustainable community development by ISO/TC 268 in 2012, and it is proposed by an accredited body with a long experience and indisputable contribution to standardization and includes measurable and consistent indicators covering the majority of urban aspects [12,23-25]. From the above, it is evident that larger amounts of urban data are required, which should be standardized to enable the synthesis of indicators which are solid and uniformly exploited.

Taking into account the above issues, it is obvious that: (i) individual KPIs cannot lead to a global SSC performance characterization when decision-making is needed, and (ii) it is necessary to increase the amount of urban data produced along with their systematic standardization, so that open data platforms are enriched and the synthesis of indicators becomes feasible $[4,13,20]$. As [12] pointed out, city managers are concerned with the "big picture" of the city, as they have limited time and monetary resources and want to get a snapshot of the city's performance in different areas without being interested in technical or methodological details. Therefore, there is a strong demand for cross-KPI interrelation and dynamic urban data feed updates that allow instant alerting and effective decision-making. Aiming to address this issue, this paper proposes a novel framework that aims to provide a comprehensive view of a city's performance by utilizing both open urban data and the ISO 37120 KPIs. The selection of ISO 37120:2018 is due to the fact that it is a mature and tested standard as it is a revision of ISO 37120:2014 Standard, is widely recognized by many researchers and practitioners, as previously mentioned, is implemented by WWCD [26] and is the parent of ISO 37122:2019 (Sustainable cities-Indicators for smart cities) [27] and ISO 37123:2019 (Sustainable cities-Indicators for resilient cities) [28] Standards, which will be discussed in Section 3. The proposed approach allows for a flexible KPI synthesis by exploiting: (i) urban data from open data platforms, and (ii) data from a citizens reporting service that enables citizens to submit their requests to the municipality. The proposed framework builds on the earlier "cityDNA" framework [29], which is redesigned and extended to identify potential interrelations between SC dimensions, in an attempt to shape the cities' profiles and to facilitate city monitoring and policy-making. The evolution of SSC over the last three years and the emerging needs for urban data utilization and cities' standardization have inspired the authors to redesign the "cityDNA" framework by adopting the ISO 37120:2018 Standard [22], which offers a suitable set of indicators to steer and measure the city's performance. The revisited framework aspires to model, generate and visualize the city's profile by offering a Web service which enables the production of standardized urban data, highlighting the importance of the participation of citizens (crowdsourcing). Specifically, KPI-driven urban data is collected and analyzed, synthesizing the "cityDNA" profile that is visualized by providing valuable information about the city performance to SSC stakeholders.

The contribution of this paper is three-fold: (i) systematically synthesizes urban data and the city's KPIs, to respond to cities' transformation and standardization under the widely adopted ISO Standard [22], (ii) introduces a flexible and adaptive benchmarking framework along with its Web service that implements the ISO 37120:2018 Standard with the aim of modeling, synthesizing and visualizing city profile and facilitating decisionmaking, and (iii) showcases the feasibility of synthesizing a city's ISO KPIs from urban data derived from both open data platforms and a citizens reporting service, under a case study and a proof-of-concept (PoC) scenario. To the best of our knowledge, "cityDNA" is the first 
framework that attempts to synthesize city profile and measure city performance using KPI-driven data and KPIs interrelations by implementing the ISO 37120:2018 Standard. The proposed framework along with a Web service aim to enhance citizen engagement and benefit SSC stakeholders (i.e., city managers, developers, researchers, etc.), since it aims to leverage user-generated content and constitutes a tool that provides easy conclusions and can help to optimize decision-making. Both the proposed framework and the Web service are dynamic and scalable, since they can be enriched with new features, be used for the implementation of city standards proposed by other standardization bodies, be used for profiling and performance measurement of other entities such as buildings, etc.

The remainder of this paper is organized as follows: Section 2 deals with the need for urban transformation and the concepts of smart cities and resilient cities. The important role of urban data and crowdsourcing in urban transformation and the related challenges to be faced by city managers are discussed in Section 3. Section 4 includes the recent efforts for cities' standardization, which is necessary for urban transformation and cities' benchmarking, as well as ISO standards for smart and resilient cities. The proposed framework and methodology that were designed to build the "cityDNA" model, which is an organic model that synthesizes and depicts the city profile and reveals city performance, are described in Section 5. A Web service, which was developed for data registration and "cityDNA" profile generation, along with a case study that concerns cities of Boston and London, which was designed to investigate the feasibility of KPI synthesis from open data and to test and validate the proposed model, are presented in Section 6. Section 7 provides a demonstration of a PoC scenario designed to investigate whether crowdsourcing data retrieved from a complaints service can be used to synthesize ISO indicators. Finally, Section 8 contains the final remarks, the limitations identified and future potentials.

\section{Smart to Resilient Cities' Transformation Principles}

Many cities around the world are striving to leverage their resources to modernize the traditional mechanisms of their operation and to acquire dynamic behavior to deal with the urban problems arising from anarchic urbanization and urban aging, and to become a pole of attraction for citizens and investors. City transformation is a complex and multidimensional process as it depends on the collective integration of governance, technology, institutional and transitional components [30]. As [31] pointed out, city transformation is based on four key areas, which are: (i) urban planning, (ii) physical infrastructure, (iii) ICT infrastructure and (iv) smart solutions' deployment, and aims at cultivating sustainability, smartness and resilience in cities. In the context of city transformation, particular emphasis is placed on modern governance models' application, the exploitation of disruptive technologies, strengthening of communities and citizen participation, environment and resources' protection and emergency management [31,32].

The concept of SC, which was launched about 20 years ago, significantly influenced the city managers and paved the way for the transformation of cities to achieve their sustainability [4]. More than 40 definitions and 30 conceptual models were proposed to clarify the term "smart city" that differ from each other due to the different perspectives and approaches developed for its modeling and design. Many SC definitions emphasize the use of ICT to effectively combine resources to make the city more interconnected, smart and viable, while some other sustainability oriented definitions focus on combining soft infrastructure (i.e., people, knowledge, communities, business processes, etc.) and the hard infrastructure (i.e., ICTs, buildings, city facilities, etc.) to provide a viable, efficient and sustainable city [33]. In the latter case, the term SSC is often used instead of the term SC. Reference [34] considers a smart (sustainable) city as an innovative city that exploits ICTs and other means, with the purpose of improving the quality of life, the efficiency of urban services and operation and competitiveness, while ensuring the needs of present and future generations regarding economic, social and environmental aspects. The improvement of the quality of life and the economy, the development of efficient urban infrastructure, ensuring social inclusion, sustainable management and conservation of natural resources 
and ensuring good governance are the main goals of SC [4]. According to the conceptual model of [35], the SC ecosystem consists of six dimensions, which are: (i) smart economy, (ii) smart governance, (iii) smart environment, (iv) smart people, (v) smart mobility and (vi) smart living.

Along with the establishment of smart city, the concept of resilient city (RC) emerged [36,37]. The term "resilience" came to the fore in 2012, after Hurricane Sandy, which caused a total of about USD 19 billion in damage, and is associated with risk management, ecology and political sciences [36]. In this context, international organizations and city associations promoted the term "resilient city" to improve cities' capabilities to deal with risks and external pressures, ranging from climate change and environmental degradation to poverty and congestion. As pointed out in [32], RCs are those that have the ability to absorb, recover and prepare for future shocks (economic, environmental, social and institutional) and promote sustainable development, well-being and inclusive growth. The COVID-19 crisis that spread around the world intensified the need to integrate resilience into local government recovery strategies [38]. The achievement of resilience in cities is driven by four interrelated areas, which are: (i) economy, (ii) environment, (iii) governance and (iv) society [32]. Citizen engagement and co-creation are also considered essential to achieving resilience in cities. Regarding this, the authors of Reference [39] proposed the redistribution of power and the redesign of urban services with the purpose of enhancing citizen participation and equality. Taking into account the abovementioned and the relevant literature $[37,40]$, it appears that RCs, through the mechanisms they develop, aim at preventing natural disasters (e.g., floods, earthquakes, hurricanes, etc.), managing emergencies (e.g., health crises, fires, etc.) effectively, civil protection and maintaining social cohesion and economic development.

Although the concepts of SCs and RCs have different roots and missions, they have many similarities, and there is an overlap of their key features, some of which are: efficiency, flexibility, learning and innovation capacity, participation, awareness, etc. The features that are unique to RCs and contribute to their adaptability are the following: persistence, modularity, redundancy, memory, robustness, resourcefulness and transformability. As far as SCs are concerned, their key features are: equity, monitoring capacity, reliability and anticipation [37]. In this respect, the McKinsey Institute [41] pointed out that "smarter cities are resilient cities", since city monitoring through smart infrastructure leads to the acquisition of profound knowledge and timely decision-making and execution of actions. Studying the differences and similarities between SCs and RCs, the authors of Reference [42] concluded that the impact of RCs is positive on smart cities from a physical, social and environmental point of view, while the impact of SCs on RCs can be both positive and negative from the above three aspects. Additionally, both SCs and RCs are equally important for urban planning and can complement each other through proper planning and governance. Therefore, city managers need to devise transformation strategies that will lead to the realization of both smart and resilient cities, to meet the challenges of rapid urbanization and to achieve sustainable urban development. Since each city has its own needs and characteristics (intrinsic and extrinsic) and there is no highroad to achieve city transformation, the acquisition of profound knowledge that will come from urban data and the use of relevant standards to steer and measure city performance are proving necessary.

\section{Cities as Data-Driven Ecosystems: Urban Data Exploitation and Crowdsourcing}

Cities act as "data prosumers", since huge amounts of data are generated and consumed on a daily basis [4]. The main driving force behind the urban data production is human activity, as people live and work in cities and manage them. The authors of Reference [4], conducting a systematic review on SC data analytics, found that the design, development and maintenance of smart services requires the exploitation of data from various urban data sources. Urban data constitutes a valuable asset of cities as its exploitation provides insights into their operation and performance, which are necessary for decision-making and urban planning [31], and as aptly pointed out by [43], "the city of 
tomorrow is designed using the data of today". In this context, several conventional cities that strive to transform into smart and resilient ones have recognized the important role of urban data and developed infrastructure for their collection and utilization [44]. However, the efficient use of urban data raises new issues related to: (i) urban data sources, (ii) data ownership and (iii) data storage and processing [44-46].

With regard to urban data sources, the majority of urban data comes from organizations, both public and private are included, that have monitoring and data recording systems or conduct surveys. The use of IoT technologies, despite the investments made in recent years, the value of which will exceed 2 trillion US dollars by 2025 [47], remains prohibitive for several cities due to their limited budgets $[5,48,49]$. Moreover, the recording of human activity that has great potential is almost negligible, since few tools have been developed for data collection by citizens, citizens have not been motivated to participate in the production of urban data that will benefit cities and themselves, while Online Social Networks (OSNs) offer limited opportunities for the exploitation of OSN data $[4,44]$. Several scholars, attempting to address these limitations, highlighted the dynamics of crowdsourcing (or crowd-sensing), since the majority of urban activities are performed and can be recorded by human capital [50-53]. Crowdsourcing, which is also known as Internet of People (IoP), constitutes a valuable and low-cost urban data source that can be used either independently or in conjunction with IoT to provide real-time data [54,55]. Citizens, using their personal devices such as smartphones, wearables, etc., act as social sensors, and create and provide valuable and real-time information and social content (or User-Generated Content (UGC)), that is impossible to be derived from other technologies (e.g., IoT, GIS, etc.) [50,52]. UGC, which is produced in three different user-centric ways (i.e., participatory sensing, opportunistic sensing, opportunistic mobile social networks), is also used to verify and validate sensor data [4,53]. According to the authors of [56], who conducted a systematic review on crowdsourcing exploitation in SC, crowdsourcing applications are used in the fields of environment, disaster management, public safety, city innovation, transportation and health, while their feasibility is affected by systems' characteristics that are cost, duration, scalability, technical support and uncertainty. UGC is often exploited in Intelligent Transport Systems (ITS), in which real-time and valid information on traffic conditions is required [48,57-59]. Specifically, the authors of Reference [48] pointed out that crowdsourcing is a key mechanism for enhancing citizen participation and collecting urban data, which is necessary for transportation planning and operations. The authors of Reference [58] proposed a multi-agent system which uses UGC and IoT data to address the problem of Vulnerable Road Users (VRUs), while the authors of [60] presented a mobile crowdsourcing-based system, entitled CrackSense, which detects urban road crack, estimating its damage degree. Beyond ITS, crowdsourcing contributes to the improvement of public services and urban life, while enhancing citizen engagement and co-creation $[4,61,62]$. Therefore, as [63] pointed out, crowdsourcing should be utilized by cities as it effectively contributes to their transformation by enhancing citizen engagement and the exploitation of untapped data that captures and reveals the vibrancy of cities and enables real-time decision-making. However, issues related to the citizens' privacy protection, data usage rights, citizens' incentives to participate and the possible malicious involvement of some citizens in crowdsourcing activities should be carefully considered.

In terms of data ownership, most of the urban data belongs to municipalities and private organizations, where it remains locked and is utilized based on their purposes and interests. As part of open government, several cities, such as London, Boston, New York City, Amsterdam, Copenhagen, Barcelona, etc., set up open data platforms and dashboards to allow urban data to be accessed and used by cities' stakeholders [26,64]. However, the open data platforms of most cities contain archival data from other public or private organizations that are updated monthly or annually, and usually do not cover the full range of activities in cities, and especially human activity. This results in the provision of limited information that is insufficient for the composition of the urban profile and its evolution over time, and reduces the potential of city managers who need rich and qualitative datasets 
for knowledge acquisition and policy-making. Cities should invest in the development of digital applications that citizens can use to provide feedback to governments quickly and inexpensively through crowdsourcing, which will be interconnected with open data platforms, to increase their interaction with citizens and to improve the quality and quantity of urban data [61].

Regarding the methods of urban data exploitation, it is common to store it in databases and then retrieve and process it and visualize the results of its analysis. This timeconsuming sequence is a brake on instant data visualization and real-time decisionmaking $[4,45,46]$. Data interoperability and integration constitutes one of the most difficult problems facing cities, as pointed out by [65]. With the purpose of addressing this issue, the large volumes of urban data generated by IoT devices and crowdsourcing activities need to be harnessed to help city applications make informed decisions on the fly. In this respect, the authors of Reference [45] presented the IES Cities platform, which was designed to streamline the development of urban applications that integrate heterogeneous datasets provided by different entities, such as citizens, municipality, IoT infrastructure and other data sources. In addition, the authors of [65] proposed a conceptual framework that aims to integrate data across the various systems of the city, urban data analytics and creation of value-added services using edge computing, cloud computing, data analytics and semantic integration. Of particular interest is the work of [46], which introduced a framework for a real-time decision support system for response during a crisis or disruption of critical infrastructure based on in-memory database technologies and urban data sources. Specifically, data that include decisions and strategies concerning urban resilience are better to be collected from the database according to current urban status and the type of disruption.

As evidenced from the above, and as the authors of [44] pointed out, the aforementioned three factors that determine both the quality and quantity of acquired urban knowledge that are necessary for the successful city transformation are highly volatile and depend on technological advancements. Cities are called upon to develop mechanisms for effective urban data management and to answer questions about urban data ownership and reliability, urban data protection, the usefulness and purpose of data collection and urban data processing and analytics methods to lay the foundations for achieving their smartness and resilience and for measuring their performance [44]. Moreover, local authorities should work closely with citizens and city stakeholders to prioritize needs, develop low-cost services that are delivered on time and achieve city transformation that accelerates urban smart growth. Special emphasis should be placed on the exploitation of crowdsourcing activities, since it offer many benefits, such as strengthening citizen participation, enhancing the city's vibrancy, decreasing costs of data production, etc. [56,63]. Consequently, cities need to invest in the development of data infrastructures and define the standards for the collection, utilization and ownership of urban data to ensure their fruitful exploitation and gain comparative advantages over other cities.

\section{Standards for Smart and Resilient Cities}

This section deals with cities' standardization, which is necessary to define the guidelines for urban transformation, to make feasible the measurement of cities' performance and to facilitate decision-making. Initially, the efforts made to define cities' indicators are discussed and then the focus is on the city standards proposed by ISO.

\subsection{Smart Cities' Standardization and Profiling}

With the purpose of achieving cities' transformation and their effective management, it is necessary to identify the urban opportunities and threats and to use metrics to evaluate policy actions and measure their impact. Since cities differ significantly in geophysical, social, economic and other characteristics, a representative set of KPIs should be created for each city [66]. These indicators enable the diagnosis and address challenges, facilitate urban design and offer cities the opportunity to monitor the progress and impact of interventions aimed at achieving smartness and resilience [67]. The importance of defining indicators is 
reflected in the work of the authors of [68], who conducted a literature review on research efforts to establish a framework of indicators for monitoring and evaluating the performance and sustainability of cities. Their findings revealed that 1152 indicators were proposed, which are categorized into six smart dimensions and the majority of them are related to the environment. According to OECD [69], indicators contribute to the policy-making process in two different ways, which are the following: (i) informing those responsible about the current conditions in the city, and (ii) providing information on the implementation of policies and their performance. Two main types of indicators were proposed: the policy-making indicators and baseline indicators (i.e., measurements of demographics, labor market, etc.). The policy-making indicators in turn are divided into four categories, which are the following: (i) input indicators which monitor effort, (ii) output indicators which monitor efficiency, (iii) outcome/result indicators which monitor effectiveness and (iv) process indicators that measure the implementation of actions [69]. Therefore, both intrinsic and extrinsic characteristics of cities that are the result of policy-making can be measured through the indicators to provide an overall view of the city by synthesizing its profile.

Regarding the aforementioned, the city profile, which consists of the city character profile and city operation profile, is a way of presenting information about cities and is created using urban data, to analyze and visualize the requirements of urban services and to provide direct or indirect decision support to stakeholders in cities [70]. The city profile that emerges from the use of indicators as a unit of information aims to improve knowledge about structural changes in urban environments and measures the impact of these transformations on the quality of life in cities [71]. In this context, several organizations and research groups involved in urban planning and sustainability developed and proposed various tools and sets of indicators for evaluating the performance of cities [67]. The proposed indicators were examined by several scholars in their attempt to evaluate and compare urban strategies and their impact on cities' evolution and sustainability [11,12,33,72-74]. The findings revealed that although the proposed indicators are effective in benchmarking, their selection is often difficult, and in many cases they do not provide a comprehensive view of city performance since they focus on specific services or dimensions $[67,72,73]$. According to [12], their selection is usually determined by factors such as the spatial scale (country, region, city and neighborhood), the development phase of the city (planning, operation), the time scale of the evaluation (annual, periodic, real-time) and the purpose of the evaluation (planning, monitoring, marketing, benchmarking).

The need to simplify the selection of indicators that will allow their profiling and benchmarking led to efforts for cities' standardization. In this regard, several standardization bodies developed standards that propose indicators for measuring city performance in terms of achieving sustainability, smartness and resilience. Specifically, ITU drafted the ITUT Y.4903/L.1603 (https:/ / www.itu.int/rec/T-REC-L.1603/en (accessed on 10 February 2020)) Recommendation, that offers general guidance to cities and provides KPIs for SSCs, and the ITU-T Y.4904/L.1604 (https:/ / www.itu.int/rec/T-REC-Y.4904/en (accessed on 10 February 2020)) Recommendation for SC maturity measurement, aiming at helping cities to achieve SDGs. On the other hand, the joint IEC and ISO working group drafted the ISO/IEC 30146 Standard in October 2019, which provides evaluation indicators and evaluation methods for measuring the functionality of different ICT systems within a city. In addition, these organizations are preparing ISO/IEC 21972, which will set out the general principles for a higher-level indicator ontology that allows the representation of the indicator definition and the data used to export the index, as well as ISO/IEC 30146, which provides evaluation indicators and evaluation methods for measuring the functionality of different ICT systems within a city [24]. The contribution of ISO in the standardization process and in the definition of appropriate indicators is also excellent, since its specialized Technical Committees, after a thorough investigation into cities, developed three city standards-for city services and quality, smart cities and resilient cities-whose indicators cover the majority of urban aspects [75]. The above standards present both similarities 
and differences between them, as they relate to cities, but differ in approaches, objectives and definition of indicators [12]. Since these standards have been recently developed, case studies need to be designed to investigate the success of their implementation and the demand for their revision and improvement.

\subsection{ISO Standards and Indicators for Smart Cities: A Synopsis}

ISO is significantly involved in cities' standardization by developing standards for both cities and the urban data required for the synthesis of KPIs. These standards are widely accepted, since they provide well-defined indicators, evaluation methods and guidance on data sources $[12,26]$. Focusing on city indicators, a family consisting of three different complementary standards was developed and proposed (Figure 1). The ISO 37120:2018 Standard [22], which is a revised version of the ISO 37120:2014 Standard and proposes indicators for city services and quality in cities [21], constitutes the basis for the development of ISO 37122:2019 [27] and ISO 37123:2019 [28] Standards, that proposed indicators for smart cities and resilient cities, respectively. These sustainability-driven standards can be used in combination to provide a holistic approach to urban sustainability and their indicators can be used by each city that undertakes to measure its performance in a comparable and verifiable way, regardless of its size and location.

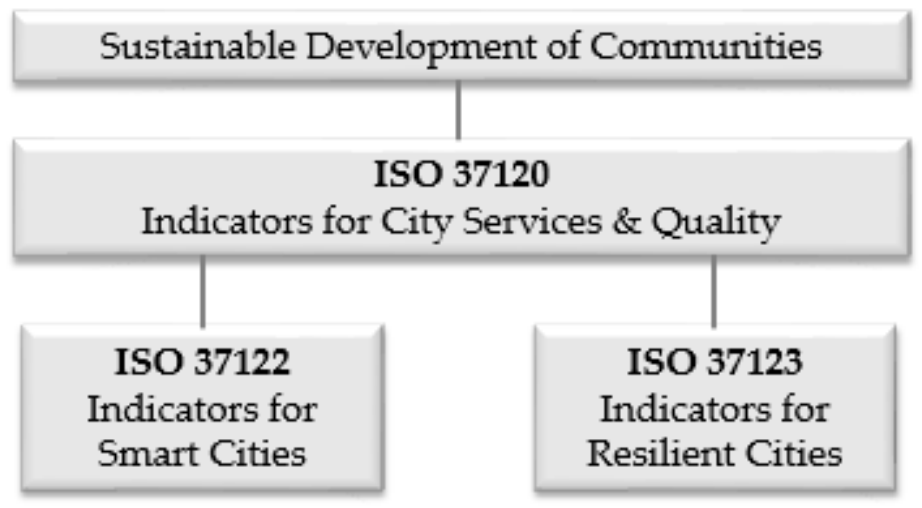

Figure 1. Sustainable development of communities—relationship between the family of city indicators' standards [22].

The indicators of the above three standards are classified into 19 themes aiming to cover all aspects of the city. Additionally, the indicators of ISO 37120:2018 per theme are divided into three subcategories, which are the following:

1. Core indicators: required to assess the effectiveness of urban services and quality of life.

2. Supporting indicators: recommended to assess the effectiveness of urban services and quality of life, and depend on the city's objectives.

3. Profiling indicators: proposed for the acquisition of statistics and the extraction of good practices resulting from the comparison between cities.

The definition of core and supporting indicators is required by the different resources and capabilities of cities worldwide. The core indicators are considered essential for guiding and evaluating the performance of cities, while the supporting indicators are used only in cities where their composition is feasible, in addition to the core ones.

ISO 37120 includes a total of 111 indicators, while ISO 37122 and ISO 37123 include 80 and 68 indicators, respectively. Taking into account the conceptual model for SC of [35] and the typology of SC core functions suggested in [2], a mapping of the ISO themes and their corresponding indicators to six SC dimensions was performed and is presented in Table 1.

1. The economy dimension, as defined in [35], concerns the competitiveness of a city, which includes entrepreneurship, innovation, productivity, the labor market, international integration and the capacity for transformation. The proposed indicators 
presented in Table 1A aim at measuring the abovementioned aspects of economy by approaching them from 3 different perspectives: ISO 37120 focuses on measuring the prosperity of the city, ISO 37122 focuses on measuring innovation and digitalization of services and ISO 37123 focuses on assessing the financial resilience of the city, and investing in the maintenance of urban assets and emergency response.

2. The governance dimension includes the interaction of city managers with citizens, the provision of public and social services, transparent governance and policymaking [35]. The ISO themes and corresponding indicators proposed for its evaluation are presented in Table 1B. ISO 37120 indicators concern the assessment of voting participation and achievement of gender equality in politics, as well as the quality of social services provided to citizens, ISO 37122 indicators concern the evaluation of e-governance, transparency and the involvement of citizens in municipal e-services and ISO 37123 indicators relate to the evaluation of urban planning for the prevention and dealing with emergencies and the achievement of urban resilience. The data required for the synthesis of these indicators is collected by and owned by municipalities. Additionally, archival data is used mainly for the synthesis of ISO 37120 and 37123 indicators, while real-time and periodic data generated by crowdsourcing activities is used for ISO 37122 indicators.

3. The environment dimension concerns the sustainable management and protection of natural resources and the environment. The issues and corresponding indicators proposed for this dimension are presented in Table 1C. Specifically, ISO 37120 proposes 31 indicators related to energy production and consumption, environmental quality, municipal waste and wastewater management, ISO 37122 proposes 24 indicators related to the exploitation of ICTs for monitoring and management of energy, the environment, solid and liquid waste and the use of alternative energy sources, with the aim of sustainability and improving the quality of life, and ISO 37123 proposes 13 indicators related to the management of extreme weather conditions and situations that threaten the ecosystem and the energy efficiency and the stability of the electricity supply network.

4. The people dimension, which includes human and social capital, the proposed theme and its indicators are presented in Table 1D. ISO 37120 proposes indicators for assessing the level of citizens' education and the provided education services, ISO 37122 proposes indicators for the evaluation of e-learning services and ISO 37123 proposes indicators for evaluating the readiness of citizens in cases of emergency and the treatment of educational interruption.

5. The mobility dimension is associated with transport and ICTs in a city, and the proposed ISO themes and their indicators are presented in Table 1E. ISO 37120 proposes 10 indicators concerning the availability and provision of both ICTs and transport services, ISO 37122 proposes 17 indicators concerning the use of ICTs in transportation management aiming at sustainability and ISO 37123 proposes 2 indicators concerning the assurance of the operation of the ICT infrastructure and the evacuation of the roads in case of emergency.

6. The living dimension includes all services related to quality of life, such as cultural and education facilities, housing quality, health conditions, safety, etc., and the proposed ISO themes and their indicators are presented in Table 1F. Specifically, ISO 37120 proposes 41 indicators related to the availability of urban facilities and the provision of services aimed at the well-being and happiness of citizens, ISO 37122 proposes 22 indicators that are related to the digitalization of urban services and the use of smart metering systems for the collection of data that is necessary for urban planning and improvement of service quality and ISO 37120 proposes 23 indicators, concerning preventive actions in order to ensure the uninterrupted provision of civil services and the well-being of citizens as well as the prevention of dangerous situations that threaten the city's prosperity. 
Table 1. Overview of ISO indicators and their mapping to city dimensions.

\begin{tabular}{|c|c|c|c|}
\hline \multicolumn{4}{|c|}{ A. Indicators for Economy } \\
\hline ISO Themes & ISO 37120:2018 & ISO 37122:2019 & ISO 37123:2019 \\
\hline Economy & $\begin{array}{ll}9 \text { KPIs (5.1-5.9) for: } \\
- & \text { labor market } \\
- & \text { entrepreneurship } \\
- & \text { urban productivity } \\
- & \text { household income } \\
- & \text { patents }\end{array}$ & $\begin{array}{ll}4 \text { KPIs (5.1-5.4) for: } \\
-\quad \text { new business } \\
-\quad \begin{array}{l}\text { labor force in ICTs, the } \\
\text { education, research and }\end{array} \\
\begin{array}{l}\text { developments sectors } \\
\text { service contracts providing } \\
\text { city services which contain } \\
\text { open data }\end{array}\end{array}$ & $\begin{array}{l}\text { 7 KPIs (5.1-5.7) for: } \\
\text { - } \quad \text { insurance coverage of the total } \\
\text { value of the assets that exist in } \\
\text { the city and disaster losses as } \\
\text { a percentage of city product } \\
\text { employment concentration, } \\
\text { labor force in informal } \\
\text { employment and household } \\
\text { disposable income }\end{array}$ \\
\hline Finance & $\begin{array}{ll}5 & \text { KPIs }(9.1-9.5) \text { for: } \\
- & \text { debt services and taxes } \\
- & \text { capital spending } \\
- & \text { own-source revenue } \\
- & \text { gross capital and } \\
& \text { operating budget }\end{array}$ & $\begin{array}{l}\text { 2 KPIs (9.1-9.2) for: } \\
\text { - city revenues collected from } \\
\text { the distribution of the } \\
\text { economy compared to own } \\
\text { resources revenues } \\
\text { - electronic payments and } \\
\text { invoices }\end{array}$ & $\begin{array}{l}\text { 7 KPIs (9.1-9.7) for: } \\
\text { - } \quad \text { expenditures on upgrades } \\
\text { and maintenance of city, social } \\
\text { and community services, } \\
\text { green and blue infrastructure } \\
\text { and emergency management } \\
\text { planning }\end{array}$ \\
\hline \multicolumn{4}{|c|}{ B. Indicators for governance } \\
\hline ISO Themes & ISO 37120:2018 & ISO 37122:2019 & ISO 37123:2019 \\
\hline Governance & 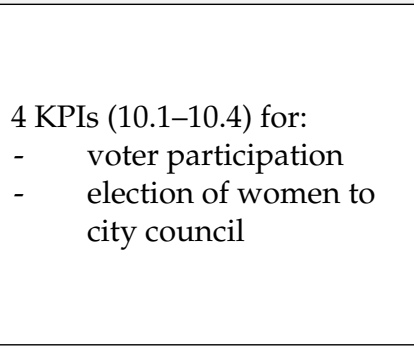 & 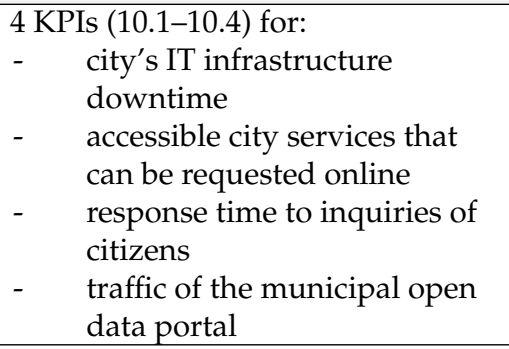 & 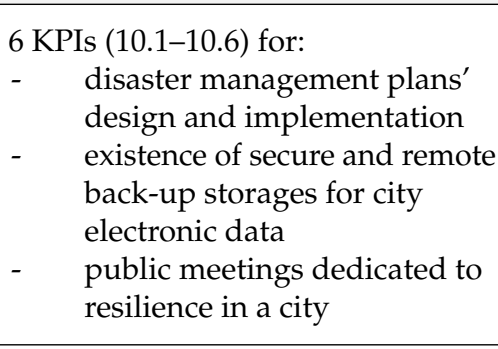 \\
\hline Urban planning & $\begin{array}{ll}5 \text { KPIs (21.1-21.5) for: } \\
-\quad \text { informal settlements } \\
-\quad \text { green area } \\
-\quad \text { jobs-housing ratio } \\
-\quad \text { basic service proximity } \\
-\quad \text { city population and } \\
& \text { built-up density }\end{array}$ & $\begin{array}{l}\text { 4 KPIs (21.1-21.4) for: } \\
\text { - } \quad \text { citizen engagement in the } \\
\text { planning process } \\
\text { - } \quad \text { building permits (spent time } \\
\text { for approval, electronic } \\
\text { submission system) }\end{array}$ & 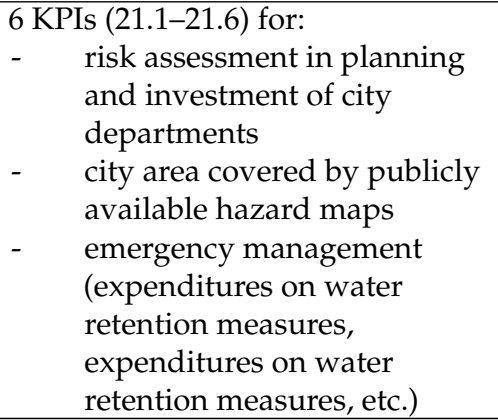 \\
\hline \multicolumn{4}{|c|}{ C. Indicators for environment } \\
\hline ISO Themes & ISO 37120:2018 & ISO 37122:2019 & ISO 37123:2019 \\
\hline Energy & $\begin{array}{l}8 \text { KPIs (7.1-7.8) which for: } \\
-\quad \begin{array}{l}\text { energy consumption in } \\
\text { private and public }\end{array} \\
\text { buildings } \\
\text { - } \quad \begin{array}{l}\text { end-use energy derived } \\
\text { from renewable sources }\end{array} \\
\text { - } \quad \begin{array}{l}\text { electrical service } \\
\text { interruptions }\end{array}\end{array}$ & 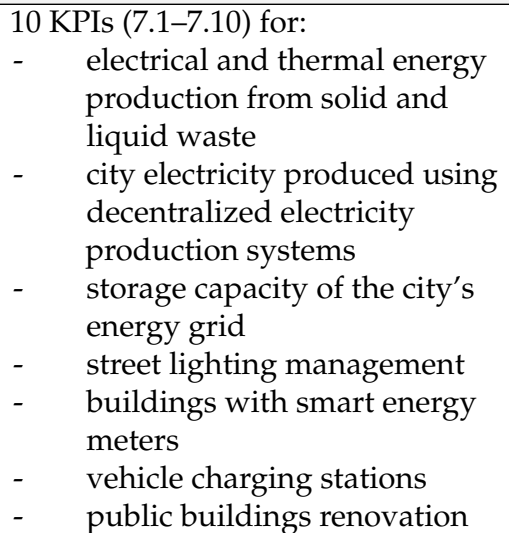 & $\begin{array}{ll}3 \text { KPIs (7.1-7.3) for: } \\
-\quad \text { energy supply capacity } \\
-\quad \text { critical facilities served by } \\
\text { off-grid energy services }\end{array}$ \\
\hline
\end{tabular}


Table 1. Cont

\begin{tabular}{|c|c|c|c|}
\hline \multicolumn{4}{|c|}{ C. Indicators for environment } \\
\hline ISO Themes & ISO 37120:2018 & ISO 37122:2019 & ISO 37123:2019 \\
\hline $\begin{array}{l}\text { Environment and } \\
\text { climate change }\end{array}$ & $\begin{array}{ll}9 \text { KPIs (8.1-8.9) which relate } \\
\text { for: } \\
-\quad \text { noise pollution } \\
-\quad \text { gas emissions } \\
-\quad \text { air quality } \\
-\quad \text { change in number of } \\
\quad \text { native species }\end{array}$ & 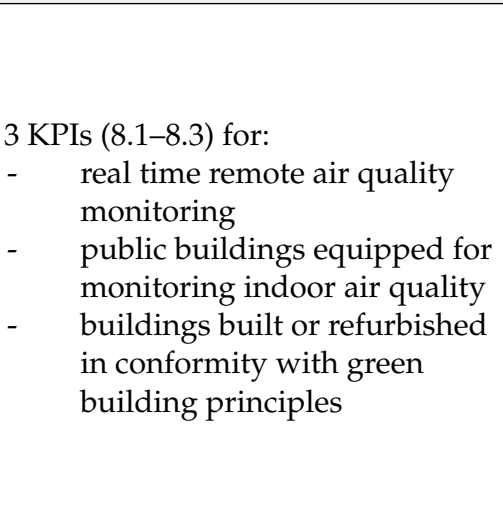 & $\begin{array}{ll}\text { 9 KPIs (8.1-8.9) for: } \\
\text { - } \quad \text { management of extreme } \\
\text { weather conditions (heat } \\
\text { events, cold events, flood } \\
\text { events, etc.) } \\
\text { - } \quad \text { management of urban heat } \\
\text { islands effect and its } \\
\text { mitigation through } \\
\text { high-albedo materials in city } \\
\text { area } \\
\text { soil restoration and ecological } \\
\text { evaluation of natural urban } \\
\text { areas for their protective } \\
\text { services }\end{array}$ \\
\hline
\end{tabular}

10 KPIs (16.1-16.10) for:

- $\quad$ solid waste generation and management

Solid waste (collection, recycling, disposal, etc.)

- hazardous waste management
6 KPIs (16.1-16.6) for: recycling of plastic and electrical and electronic waste

- $\quad$ sensor-enabled garbage bins and drop-off center equipped with telemetering

- $\quad$ energy generation from urban waste

- door-to-door garbage collection with an individual monitoring of household waste quantities

5 KPIs (22.1-22.5) for:

- $\quad$ treated wastewater and bio solids reuse

4 KPIs (22.1-22.4) for

Wastewater wastewater management and sanitation

energy generation from wastewater wastewater pipeline network monitoring by real-time data-tracking sensor systems

\section{Indicators for people}

ISO Themes

ISO 37120:2018

ISO 37122:2019

\section{KPIs (6.1-6.6) for:}

Education

- educational attainment

- $\quad$ teacher capacity level of citizens

3 KPIs (6.1-6.3) for: digital learning devices' usage

- $\quad$ STEM higher education

- $\quad$ city population with professional proficiency in more than one language more than one lan

\begin{tabular}{ccll}
\hline & & E. Indicators for mobility & \\
\hline ISO Themes & ISO 37120:2018 & \multicolumn{1}{c}{ ISO 37122:2019 } & \multicolumn{1}{c}{ ISO 37123:2019 } \\
\hline \multirow{3}{*}{ Telecommunication } & $\begin{array}{l}\text { 3 KPIs (18.1-18.3) for: } \\
\text { and mobile phone connections }\end{array}$ & $\begin{array}{l}\text { Internet services speed and } \\
\text { quality } \\
\text { public Internet access }\end{array}$ & $\begin{array}{l}\text { 1 KPI (18.1) for emergency } \\
\text { equipment able to operate reliably } \\
\text { during a disaster event }\end{array}$ \\
\hline
\end{tabular}

1 KPI (16.1) for active and temporary waste management sites available for debris and rubble
$(-)$ 
Table 1. Cont.

\begin{tabular}{|c|c|c|c|}
\hline \multicolumn{4}{|c|}{ E. Indicators for mobility } \\
\hline ISO Themes & ISO 37120:2018 & ISO 37122:2019 & ISO 37123:2019 \\
\hline Transportation & $\begin{array}{ll}8 \text { KPIs (19.1-19.8) for: } \\
- & \text { public transportation } \\
- & \text { commuting } \\
- & \text { bicycle paths and lanes } \\
- & \text { transportation deaths }\end{array}$ & 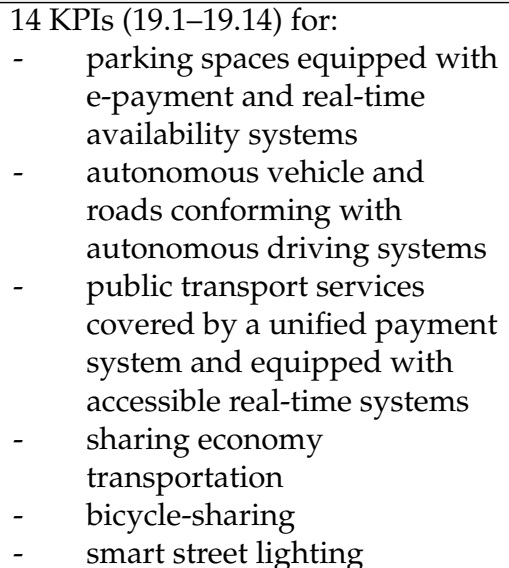 & $\begin{array}{l}1 \mathrm{KPI}(19.1) \text { for available evacuation } \\
\text { routes in a city }\end{array}$ \\
\hline \multicolumn{4}{|c|}{ F. Indicators for living } \\
\hline ISO Themes & ISO 37120:2018 & ISO 37122:2019 & ISO 37123:2019 \\
\hline Health & $\begin{array}{ll}\text { 6 KPIs (11.1-11.6) for: } \\
-\quad \text { life expectancy and } \\
\text { mortality } \\
-\quad \text { suicides } \\
-\quad \text { medical and } \\
& \text { paramedical staff } \\
\text { capacity }\end{array}$ & $\begin{array}{l}\text { 3 KPIs (11.1-11.3) for: } \\
\text { - } \quad \text { e-patient services (online } \\
\text { unified health file, remote } \\
\text { medical appointments) } \\
\text { - } \quad \text { ity population access to } \\
\text { real-time public alert systems } \\
\text { for air and water quality } \\
\text { advisories }\end{array}$ & $\begin{array}{l}\text { 4 KPIs (11.1-11.4) for: } \\
-\quad \text { population immunization and } \\
\text { health insurance } \\
\text { - } \quad \begin{array}{l}\text { adequacy of electricity supply } \\
\text { to hospitals }\end{array} \\
\text { - } \quad \text { infectious disease outbreaks }\end{array}$ \\
\hline Housing & $\begin{array}{l}5 \text { KPIs (12.1-12.5) for: } \\
-\quad \text { housing quality }\end{array}$ & $\begin{array}{l}2 \text { KPIs (12.1-12.2) for smart energy } \\
\text { and smart water meters }\end{array}$ & $\begin{array}{l}\text { 6 KPIs (12.1-12.6) for: } \\
-\quad \text { vulnerability of residential } \\
\text { buildings in high-risk hazards } \\
\text { (flood, disasters) and } \\
\text { residential cities not in } \\
\text { conformity with building } \\
\text { standards } \\
\text { - capacity of designed } \\
\text { emergency shelters } \\
\text { - } \quad \text { restoration of buildings } \\
\text { damaged by disasters } \\
\end{array}$ \\
\hline $\begin{array}{l}\text { Population and } \\
\text { social conditions }\end{array}$ & $\begin{array}{l}4 \text { KPIs (13.1-13.4) for: } \\
-\quad \text { poverty and inequality }\end{array}$ & 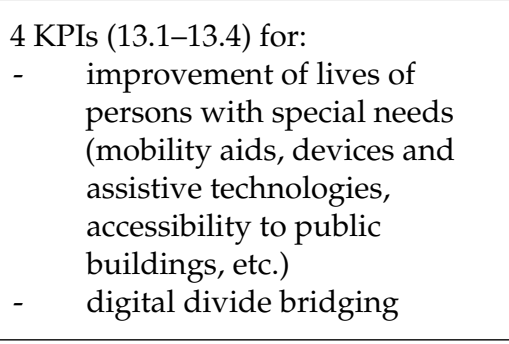 & $\begin{array}{ll}\text { KPIs (13.1-13.5) for: } \\
-\quad & \text { vulnerable population } \\
-\quad & \text { population affected by natural } \\
\text { hazards } & \text { population enrolled in social } \\
\text { - } & \begin{array}{l}\text { assistance programs } \\
\text { neighborhood with regular } \\
\text { and open neighborhood } \\
\text { association }\end{array} \\
\end{array}$ \\
\hline Recreation & $\begin{array}{l}2 \text { KPIs (14.1-14.2) for indoor } \\
\text { and outdoor recreation spaces }\end{array}$ & $\begin{array}{l}1 \mathrm{KPI}(14.1) \text { for online booking of } \\
\text { public recreation services }\end{array}$ & $(-)$ \\
\hline
\end{tabular}


Table 1. Cont.

\begin{tabular}{|c|c|c|c|}
\hline \multicolumn{4}{|c|}{ F. Indicators for living } \\
\hline ISO Themes & ISO $37120: 2018$ & ISO 37122:2019 & ISO 37123:2019 \\
\hline Safety & 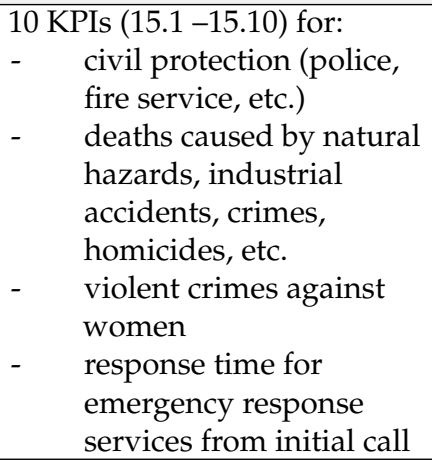 & $\begin{array}{l}1 \mathrm{KPI}(15.1) \text { for city area covered by } \\
\text { digital surveillance cameras }\end{array}$ & 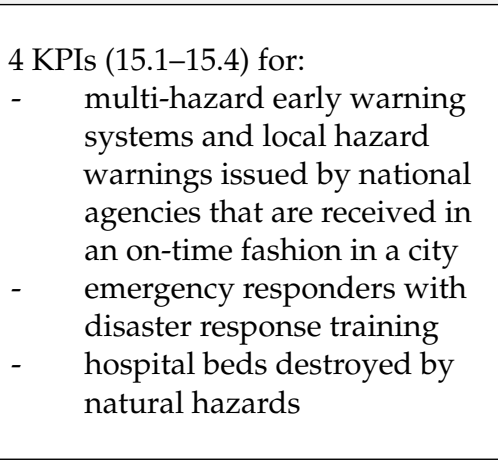 \\
\hline Sport and culture & $\begin{array}{l}3 \text { KPIs (17.1-17.3) for cultural } \\
\text { and sport facilities and } \\
\text { cultural events }\end{array}$ & 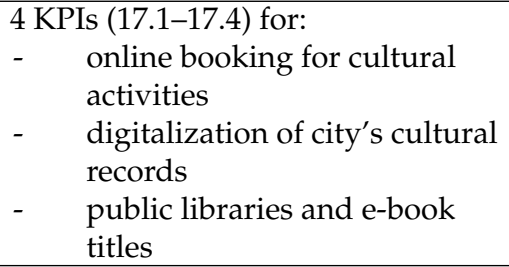 & $(-)$ \\
\hline $\begin{array}{l}\text { Urban/local } \\
\text { agriculture and } \\
\text { food security }\end{array}$ & $\begin{array}{l}\text { 4 KPIs (20.1-20.4) for: } \\
-\quad \begin{array}{l}\text { malnutrition and } \\
\text { overfeeding of the } \\
\text { population }\end{array} \\
\text { - } \quad \begin{array}{l}\text { urban agriculture and } \\
\text { local food production }\end{array}\end{array}$ & $\begin{array}{ll}\text { 3 KPIs (20.1-20.3) for: } \\
-\quad \text { municipal budget spent on } \\
\text { - } & \text { urban agriculture initiatives } \\
\text { composting of collected } \\
\text { municipal food waste } \\
\text { - } & \begin{array}{l}\text { city's land area covered by an } \\
\text { online food-supplier system }\end{array}\end{array}$ & $\begin{array}{l}2 \text { KPIs (20.1-20.2) for: } \\
-\quad \text { citizens' proximity to grocery } \\
\text { stores } \\
\text { - } \quad \begin{array}{l}\text { capacity of city food reserves } \\
\text { in case of emergency }\end{array}\end{array}$ \\
\hline Water & $\begin{array}{l}\text { 7 KPIs (23.1-23.7) for: } \\
-\quad \text { domestic water } \\
\text { consumption } \\
\text { - } \quad \text { water quality (water } \\
\text { service interruptions, } \\
\text { city population with } \\
\text { potable water supply } \\
\text { service, etc.) }\end{array}$ & $\begin{array}{l}4 \text { KPIs (23.1-23.4) for water quality } \\
\text { monitoring and water distribution } \\
\text { using smart meters and smart water } \\
\text { systems which provide real-time } \\
\text { data }\end{array}$ & $\begin{array}{ll}2 \text { KPIs (23.1-23.2) for: } \\
-\quad & \text { alternative water sources } \\
- & \text { alternative methods for } \\
\text { drinking water }\end{array}$ \\
\hline
\end{tabular}

The number of indicators per dimension for each of the ISO Standards is shown in Figure 2. Considering the total number of indicators per dimension, it appears that the majority of indicators are associated with the dimensions of the living and environment, followed by the dimensions of the economy and mobility, governance and people. A similar trend is followed by the indicators of ISO 37120, which concerns city services and quality of life. With regard to ISO 37122, which concerns SCs, it appears that the majority of its indicators relate to the dimensions of environment, living, mobility and governance. This fact is justified, since ICTs have been widely used in recent years, aiming at the development of smart services related to these dimensions, and the measurement of cities' performance is considered necessary. Finally, as expected from the definition and aspects of RCs, the majority ISO 37123 indicators are associated with the dimensions of living, economy, environment and governance.

Regarding the urban data required for the synthesis of the indicators proposed by ISO standards, the following conclusions are drawn:

1. Indicators related to the dimensions of economy and people mainly require archival data that are collected by public organizations (e.g., municipalities, chambers, labor organizations, tax services, ministry of education, etc.) and belong to local, regional and national authorities.

2. The indicators proposed by ISO 37120 and ISO 37123, which concern the dimensions of governance, environment, mobility and living, require mainly archival data (e.g., data 
related to installed electric power, number of landfills, power generation mix, statistics for air pollution, etc.), which is collected and belongs to local, regional and national authorities. Additionally, the synthesis of some indicators requires the exploitation of real-time data, which is generated and collected by urban infrastructure and belongs to either local authorities or private companies.

3. The indicators proposed by ISO 37122, which concern the dimensions of governance, environment, mobility and living, require mainly real-time data generated from the installed infrastructure owned either by local authorities or private companies, and from personal devices that are used by citizens to record their activities (e.g., energy consumption, amount of discarded solid waste, online booking, e-payments, etc.). This demand for real-time data utilization is due to the fact that these dimensions include services that affect the quality of life and performance of the city on a daily basis, and therefore real-time monitoring is required to enable immediate interventions.

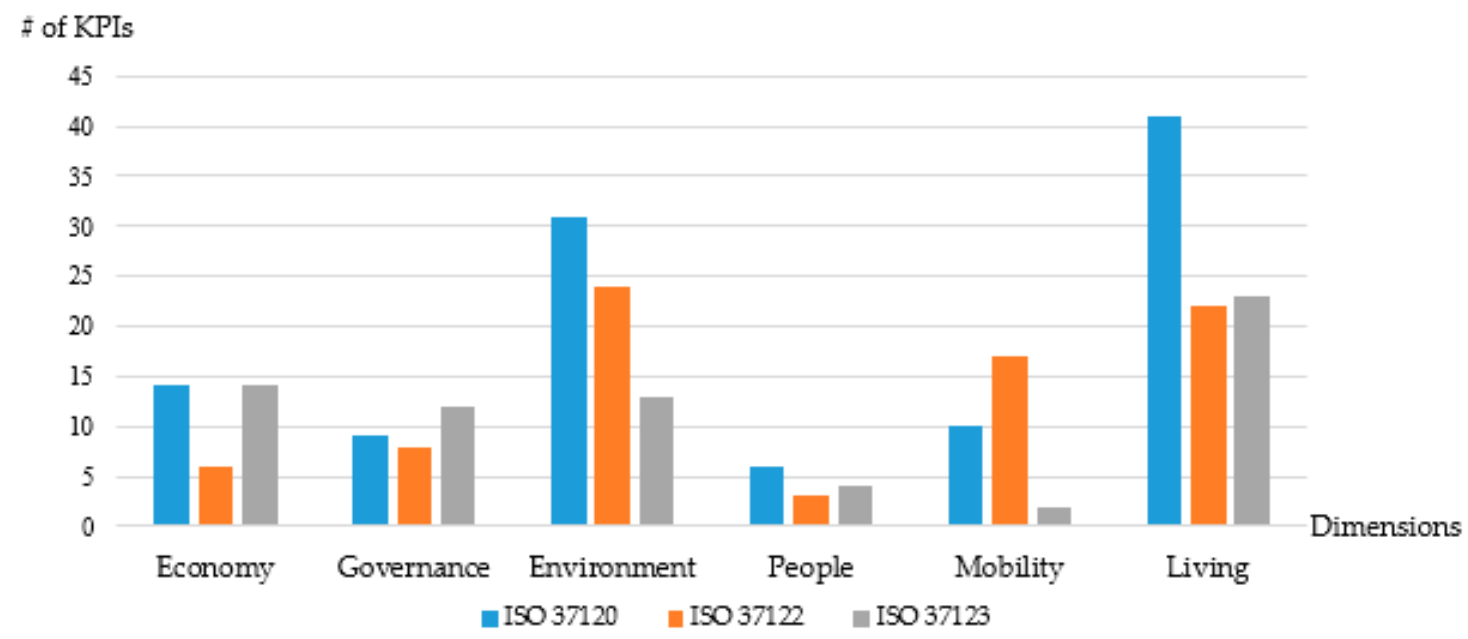

Figure 2. Number of KPIs per city standard and SC dimension.

Based on the previous discussion on the demand for cities' standardization and the standards for cities proposed by ISO, the next core observations and open issues require further consideration:

1. Different indicators are included in each standard aiming at the evaluation of different aspects of cities. Specifically, ISO 37120 includes indicators that measure mainly the quality of life and services in cities, ISO 37122 includes indicators that measure the exploitation of ICTs in urban services, while the indicators of the standard ISO 37123 aim at measuring the readiness of the city in dealing with emergencies and its resilience. Therefore, these standards can be used either separately by synthesizing the city profile and measuring city performance based on the indicators they include, or in combination by synthesizing the overall profile of the city and measuring its overall performance.

2. The proposed indicators, which were defined and proposed after a thorough investigation and study by the ISO Technical Committees to provide a comprehensive view of the cities, focus unilaterally on specific urban services and aspects, ignoring the rest, which are probably important for other cities. As pointed out in [12], further analysis of the needs of cities and the enrichment of existing standards with new indicators is required to capture the overall city profile.

3. The identification of the proposed indicators requires the existence and exploitation of relevant KPI-driven urban data. In this respect, it appears that the majority of indicators are determined by archival data, which is collected by various organizations (i.e., local authorities, private companies, citizens, etc.) and becomes available to local authorities for consumption and sharing through their open data platforms [18]. 
In addition, real-time data is required for the synthesis of the indicators proposed by ISO 37122. However, the existence and availability of KPI-driven urban data remains limited in several cities worldwide. This is due either to the lack of resources required to develop the appropriate infrastructure for data collection and management, or to the lack of standardization of urban data and to the limited exploitation of crowdsourcing activities. Recognizing the demand for city standardization and benchmarking, WWCD, which is the global leader in standardized city data aiming at creating smart, sustainable, resilient and prosperous cities, has developed the WCCD Global Cities Registry (https: / /www.dataforcities.org/global-cities-registry (accessed on 10 February 2020)), that is the internationally recognized list of cities certified according to ISO 37120 and its certification system. The certification concerns the cites' data that are verified and comply with ISO 37120, which are then published in the WCCD Open Data Portal for a period of one year, offering city-to-city comparisons, data analytics and visualization.

4. The proposed indicators are common to all cities that differ in their intrinsic and extrinsic characteristics. As [19] pointed out, each city has its own peculiarities, and for this reason, they have to adapt the ISO standards and international best practices based on them, in order to achieve their transformation. As a result, the synthesis of ISO indicators may not be feasible for some cities since they may not support the services listed in these standards or may not have relevant data.

5. In the context of urban standardization, it would be practical to study and to set up a city model, which will become the reference city, and the indicators will have the ideal values for achieving smartness and resilience. According to [20], the standards developed in ISO 37120 do not provide recommended values or thresholds for cities, but provide what and how to measure ambitiously to help cities compare and evaluate performance metrics. The definition of a reference city requires a lot of effort since cities differ from each other, and they should be categorized based on their common characteristics (e.g., size, location, socio-economic situation, etc.). However, it will facilitate benchmarking of cities and the adoption of best practices for urban improvement.

In the context of addressing the aforementioned open issues, the "cityDNA" framework was designed and developed, which is discussed in detail in the next section.

\section{An Organic Model for Smart City Benchmarking}

The proposed "cityDNA" framework is presented herein. Initially, the basic principles of the revised framework and its differences from the original "cityDNA" framework on which it was based are discussed, and then the design and development of the "cityDNA" model is presented.

\subsection{The cityDNA Framework Principles and Outline}

Taking into account the evolution of SSC and the current challenges associated with city transformation and standardization and the demand for urban data production and exploitation, the idea of the "cityDNA" framework [25] came back to the forefront. This framework, inspired by biology and human DNA, considers that a city is a "living organism" whose life and evolution are shaped by multiple interactions and reciprocities. Indeed, the "green" or "eco" [76] (and the "circular" [77], recently) city SSC approaches introduced the concept of "healthy city" [78]: "the city that continually creates and improves its physical and social environments and expands the community resources that enable people to mutually support each other in performing all the functions of life and developing to their maximum potential." In other words, the city should aim to improve the local community's well-being, health and livability, and in this respect, interventions address improving the city system's behavior (transportation, water, food, emission, energy efficiency, coherence) and resilience. Under this lens and following the way human DNA provides information about human health that changes over time as the body matures [79], 
the proposed "cityDNA" framework models, synthesizes and visualizes the city profile, providing valuable information about city performance and its evolution. Since the city acts as a living organism, the term "city health" is used instead of the term "city performance". The visualized "city profile" that contains the profound information about city health is expected to facilitate the work of SSC managers and to lead to the savings of resources such as time, human effort, etc. The basic principles on which the design and development of the "cityDNA" framework were based are the following:

1. City is a "living organism" that inherits its past (economy, environment, governance, people, living, mobility) and shapes its future based on its current conditions (infrastructures) and choices (planning).

2. City is considered as a six-dimensional system, as it were defined by [35].

3. KPIs proposed by ISO 37120:2018 Standard [22] are used for "cityDNA" synthesis.

4. KPI-driven urban data retrieved from open data platforms is used for KPI synthesis.

The revisited "cityDNA" framework is presented in Figure 3. As shown, the "heart" of the "cityDNA" framework is a Web service through which the data registration and processing were performed for the purpose of synthesis and visualization of the city profile, which is offered to SSC stakeholders (i.e., city managers, urban planners, researchers, practitioners, engineers, etc.). Specifically, heterogeneous data retrieved from various data sources, such as open municipal data platforms, crowdsourcing activities, IoT, etc., is registered into the Web service through a custom rule-based uploader to ensure the selective input of urban data that will allow the synthesis of the indicators. The synthesis of KPIs is carried out using numerical data, which relates exclusively to KPIs for which it is used and is available for at least the last two years. The "city profile" is then synthesized automatically according to the "cityDNA" model (see the next subsection) and displayed on a dashboard from which it is made available to SSC stakeholders. The "city profile" is depicted in the form of the "cityDNA" double helix (Figure 3), which changes color based on the health of the city (i.e., green: healthy (ideal) cityDNA, red: mutated cityDNA, yellow: unhealthy cityDNA) and evolves over time, reflecting the changes that occur in the city.

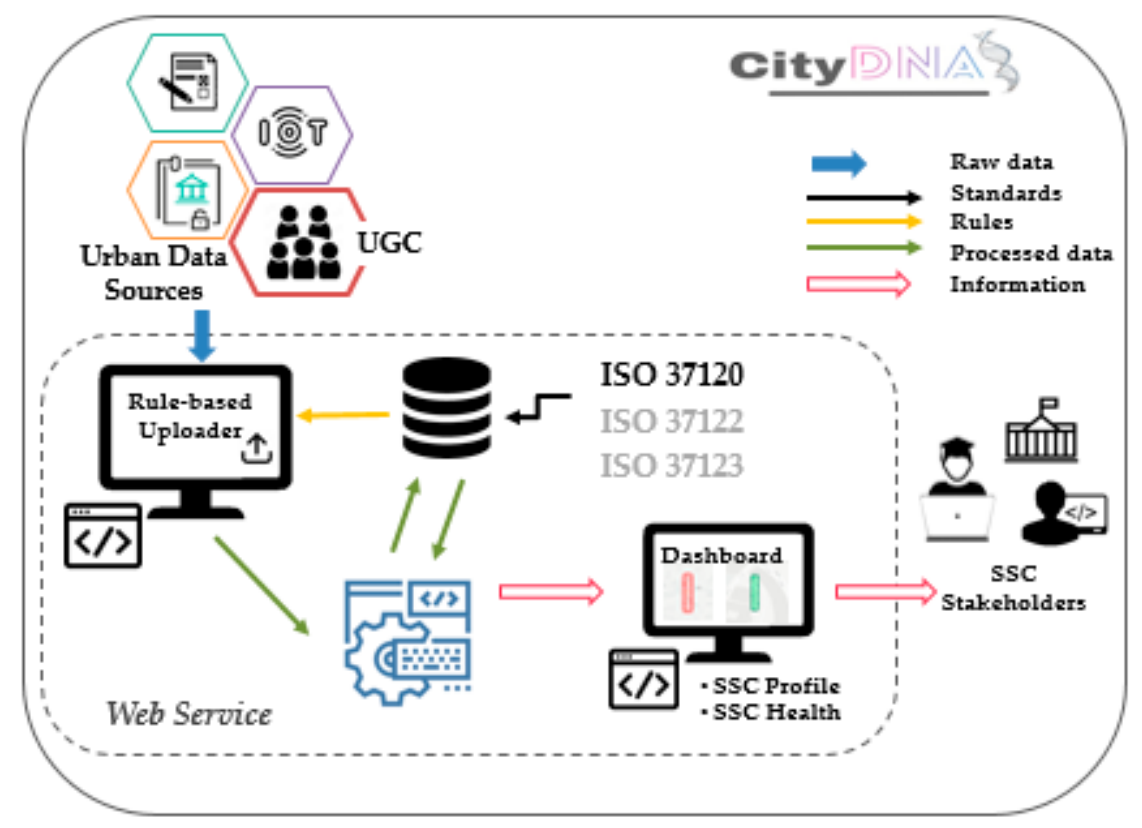

Figure 3. The integral "cityDNA" framework overview.

The revisited framework differs significantly from the original "cityDNA" framework presented in our previous work [25], since it aspires to contribute to SSC standardization and measurement of "city performance," as well as focus on the exploitation of UGC. The 
core idea on which these two frameworks are based is the synthesis and visualization of the city profile using heterogeneous urban data and adopting the basic principles of the DNA model, as it is defined in biology. However, the original "cityDNA" is a conceptual framework that aimed to utilize data from OSNs, open data platforms and an optional mobile application to synthesize the city profile, while the revisited "cityDNA" is a welldefined and implemented framework that is based on ISO 37120 and exploits KPI-driven data from valid open data platforms and crowdsourcing activities to synthesize the city profile and measure city performance through a custom Web service. This Web service is the "heart" of the revisited framework, since it constitutes the "cityDNA" profile generator, performing and monitoring all the required processes.

\section{2. "cityDNA" Model Building}

Inspired by the original "cityDNA" model [25], the revisited "cityDNA" model was designed and implemented by adopting the basic principles of human DNA and exploiting the KPIs introduced by ISO 37120 Standard. The proposed model is an "organic" model [80] that combines urban data with ISO standards into a unified whole and investigates interrelations of SC dimensions aiming to profile a city, which is a living organism that evolves over time. ISO 37120 was selected for the following reasons: (i) it was developed by ISO, which is a leading standardization body, (ii) it constitutes the revised version of ISO 37120:2014 that has already been tested, (iii) it is the parent of ISO 37122 and 37123 Standards, which follow a similar philosophy offering the opportunity to expand the exploitation of the proposed model, and (iv) it is widely recognized [24,26,75].

The human DNA is the basic unit of heredity and evolution, which stores information about the state of human health and reveals any potential disorders [79]. DNA, also known as double helix, consists of two intertwined strands forming a spiral (Figure 4a). These strands are held together by the bonds that exist between four chemical bases: adenine $(A)$, guanine $(G)$, thymine $(T)$ and cytosine $(C)$. The DNA bases are combined with each other, forming complementary pairs (A with $T$ and $C$ with $G$ ), and the order or sequence of their pairs determines the available information for the construction and maintenance of a human organism [81]. The adoption of the aforementioned concepts of human DNA led to the design and development of the "cityDNA" model (Figure $4 \mathrm{~b}, \mathrm{c})$, which synthesizes and visualizes the "city profile" (i.e., "cityDNA" profile) and provides information about "city performance" (city health) through the exploitation of KPI-based data related to cities' dimensions and services. Specifically, Figure $4 \mathrm{~b}$ illustrates a snapshot of a healthy "cityDNA", where the bonds between the dimensions are strong and the double helix is well-formed, while Figure $4 \mathrm{~b}$ depicts a snapshot of a mutated "cityDNA", where bonds between the dimensions do not develop and its helix shape is de-formed.

Since the synthesis and behavior of human DNA is very complex and it is not feasible to simulate it, the modeling of the city DNA was carried out using "heuristics" [82]. The assumptions made about the design and development of the model that is used for "cityDNA" profile synthesis are as follows:

1. The "cityDNA" profile, similar to human DNA, is a snapshot of the "cityDNA" double helix that reflects the current city profile and reveals the state of city health.

2. The "cityDNA" double helix consist of two strands that are held together by bonds.

3. Each strand consists of three city dimensions (triplet) whose states change over time.

4. Each city dimension is described by a single KPI rather than multiple KPIs, as in reality. Since cities are complex ecosystems and the identification of each of the six dimensions requires the exploitation and combination of many KPIs, this simplification is performed to avoid the complexity of the calculations in this initial phase of the "cityDNA" model development.

5. Each city dimension is described by at least one KPI which is defined as follows:

- $\quad \mathrm{D}_{\mathrm{i}}=(\mathrm{x} / \mathrm{y}) \times 100$, where $\mathrm{i}=1$ (ecn), 2 (gov), 3 (ppl), 4 (env), 5 (liv), 6 (mob) and $\mathrm{D}_{\mathrm{i}} \in[0,1], \mathrm{y}$ : strategic objective defined by the city to address the SSC challenges, and $x$ : the achieved value. For instance, in the case of KPI 7.1 (ISO 37120), that is 
related to total end-user energy consumption per capita (GJ/year), $x$ is defined as the actual value, while $y$ is defined as the ideal value of end-user energy per capita that should have been consumed based on the municipality's energy policy.

6. Definition of reference cities (city with the best/worst performance) for the development of a benchmarking metric between them and the city under consideration.

7. The data used for the synthesis of the indicators come from well-intentioned users who are interested in the city in which they live.

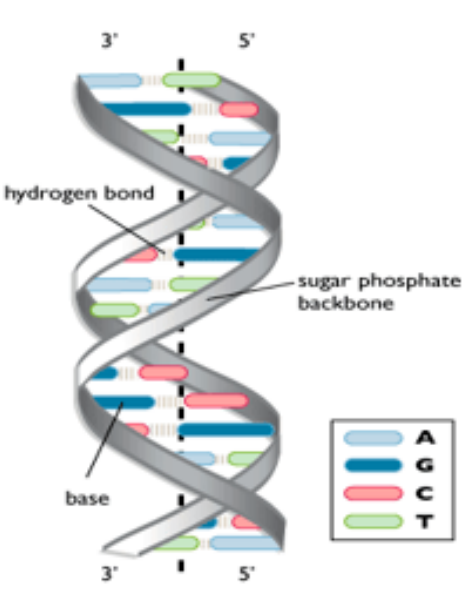

(a)

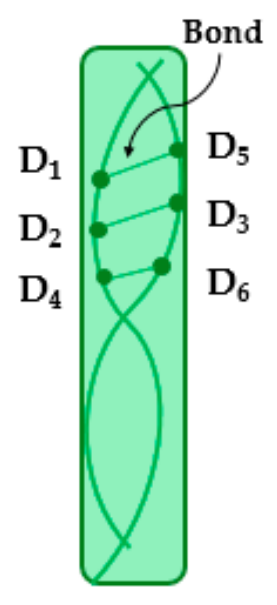

(b)

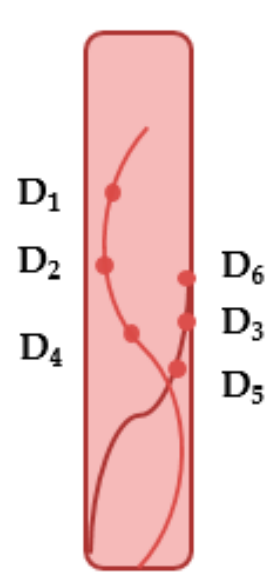

(c)

Figure 4. Human DNA vs. cityDNA: (a) human DNA, (b) healthy cityDNA, (c) mutated cityDNA. follows:

Following the above assumptions, the development of the "cityDNA" model is as

Initially, a KPI is selected for each of the six dimensions, and then the correlations between the three individual dimension pairs are calculated since the two triplets form the strands of the "cityDNA" helix. For instance, assuming that the pairs of dimensions are: economy-mobility, living-environment, people-governance and KPIs 5.7, 19.2, 13.1, 7.1, 6.3 and 10.3 (ISO 37120) are selected, then the correlations of the indicators 5.7-19.2, 13.1-7.1 and 6.3-10.3 are calculated, respectively. It is noted that the selection of dimension pairs and KPIs is determined exclusively by the user based on the purpose of his research. Taking into account that correlation coefficient ( $\mathrm{r}$ ) values range from -1 to 1 , the result of this calculation leads to the determination of the bond types of six dimensions shown in Figure 5, which are defined as follows:

- $\quad$ Positive and weak bond (PW bond): $0 \leq \mathrm{r} \leq 0.5$.

- Positive and strong bond (PS bond): $0.5<\mathrm{r} \leq 1$.

- Negative and weak bond (NW bond): $-0.5 \leq \mathrm{r}<0$.

- Negative and strong bond (NS bond): $-1 \leq \mathrm{r}<-0.5$.

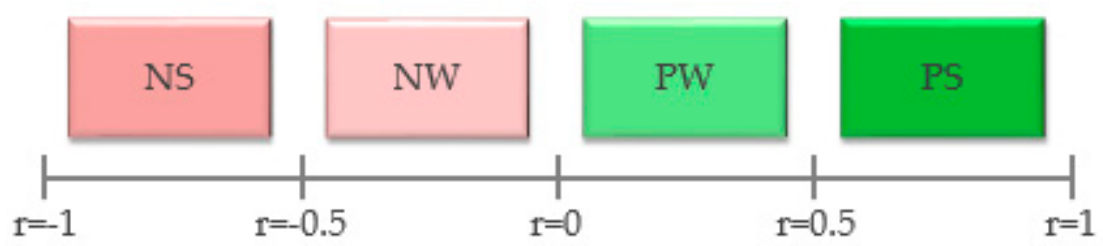

Figure 5. The "cityDNA" bond types.

Then, the combination of bond types between the dimensions' pairs is investigated to determine how strongly the two strands are connected. It is noted that if the values of dimensions' bond types ( $\mathrm{r}$ ) change in the same direction (increase, decrease), then the 
strands' bond is strong and there is no mutation. On the contrary, when they change in opposite directions, then a mutation is detected. For instance, if the pairs of six dimensions form PS bonds, then the connection between two strands is very strong, whereas if the pairs of six dimensions form NS bonds, then the connection between two strands is very weak. Therefore, as the bonds between the dimensions change from PS to NS, the bond (connection) between the two strands of the helix becomes weaker and the shape of the double helix deteriorates. The helix mutation begins when one of the bonds of the three pairs of dimensions becomes NS.

Subsequently, the indicators of each dimension are compared with the corresponding indicators of the examined (reference) cities'/countries' dimensions ( $\mathrm{Di}, \mathrm{r}+, \mathrm{Di}, \mathrm{r}-$ ) to determine the sign that will characterize the "cityDNA" helix and the deviation of the examined indicators from the respective reference indicators. However, every city system is different, and no "ideal city" exists, but, like the SSC standards, the performance of specific indicators varies. Given that reference cities are not yet defined by the proposed standards, the reference cities were selected for each KPI based on recent city rankings. It should be noted that reference cities may change annually, since performance metrics may change. In addition, in case of a lack of data for the reference cities, the next city is selected from the ranking list. Additionally, in case there is no data for a city, then data for a country is used, as it is a larger entity for which there is usually data.

The final sign of the helix is determined by combining the individual signs of dimensions, as presented in Table 2. If the majority of these KPIs is closer to the corresponding KPIs of the best reference city/country, then the final sign is positive (+), otherwise the final sign is negative (-). Aiming to build a strict model, it was considered that the neutral sign $(<>)$ is achieved when four of the six indicators are closer to the values of the respective indicators of the reference cities. Regarding the measurement of the deviation between the indicators, two metrics were defined, called "Level" and "Risk", which are characterized by the values of the intervals [A-J] and [J-A], respectively (i.e., Level A, Risk A, etc.) (Table 3). These metrics, which indicate the value of the sum of the percentages of distances of $\mathrm{Di}$ from $\mathrm{Di}, \mathrm{r}+$ and $\mathrm{Di}, \mathrm{r}-$, were defined starting from the determination of Level A and Risk J, for which the percentage distance is $10 \%$ for each dimension, and $60 \%$ for six dimensions were set (the best cases). For instance, if the percentage distance of five of the six dimensions from $\mathrm{Di}, \mathrm{r}+$ is $10 \%$ and for the sixth city dimension is $50 \%$, then their total sum is $100 \%$, so the helix is classified as Level B. Similarly, if the percentage distance of five of the six city dimensions from $\mathrm{Di}, \mathrm{r}-$ is $20 \%$ and for the sixth city dimension is $80 \%$, then their total sum is $180 \%$, so the helix is classified as Risk H. The use of Level and Risk metrics is very important since they provide a clear view for the comparison of the examined cities from the reference cities and enrich the proposed "cityDNA" model with more characteristics to better reflect the city's profile and performance.

Table 2. Sign identification based on comparison with the reference cities.

\begin{tabular}{ccc}
\hline $\mathbf{D}_{\mathbf{i}}$ Closest to $\mathbf{D}_{\mathbf{i}, \mathbf{r}}+$ & $\mathbf{D}_{\mathbf{i}}$ Closest to $\mathbf{D}_{\mathbf{i}, \mathbf{r}}-$ & ciyDNA Helix Sign \\
\hline $6 / 6$ & $0 / 6$ & + \\
$5 / 6$ & $1 / 6$ & + \\
$4 / 6$ & $2 / 6$ & $->$ \\
$3 / 6$ & $3 / 6$ & - \\
$2 / 6$ & $4 / 6$ & - \\
$1 / 6$ & $5 / 6$ & - \\
$0 / 6$ & $6 / 6$ & - \\
\hline
\end{tabular}


Table 3. Sum of percentage distances (SPD) of Di from Di, r+ and Di, $r-$.

\begin{tabular}{cccc}
\hline SPD of $\mathbf{D}_{\mathbf{i}}$ from $\mathbf{D}_{\mathbf{i}, \mathbf{r}} \boldsymbol{r}^{-}$ & Level & SPD of $\mathbf{D}_{\mathbf{i}}$ from $\mathbf{D}_{\mathbf{i}, \mathbf{r}}-$ & Risk \\
\hline $0-60 \%$ & $\mathrm{~A}$ & $540.01-600+\%$ & $\mathrm{~A}$ \\
$60.01-120 \%$ & $\mathrm{~B}$ & $480.01-540 \%$ & $\mathrm{~B}$ \\
$120.01-180 \%$ & $\mathrm{C}$ & $420.01-480 \%$ & $\mathrm{C}$ \\
$180.01-240 \%$ & $\mathrm{D}$ & $360.01-420 \%$ & $\mathrm{D}$ \\
$240.01-300 \%$ & $\mathrm{E}$ & $300.01-360 \%$ & $\mathrm{E}$ \\
$300.01-360 \%$ & $\mathrm{~F}$ & $240.01-300 \%$ & $\mathrm{~F}$ \\
$360.01-420 \%$ & $\mathrm{G}$ & $180.01-240 \%$ & $\mathrm{G}$ \\
$420.01-480 \%$ & $\mathrm{H}$ & $120.01-180 \%$ & $\mathrm{H}$ \\
$480.01-540 \%$ & $\mathrm{I}$ & $60.01-120 \%$ & $\mathrm{I}$ \\
$540.01-600+\%$ & $\mathrm{~J}$ & $0-60 \%$ & $\mathrm{~J}$ \\
\hline
\end{tabular}

Finally, the combination of the above cases leads to the definition of thirteen different states of the cityDNA model. These states fall into four categories, which are the following: (i) ideal (healthy), (ii) normal (healthy), (iii) abnormal (unhealthy) and (iv) mutated. The overall description of the "cityDNA" model is presented in Table 4. The thirteen different states in combination with the metrics "Level" and "Risk" create a wide set of "cityDNA" profiles, offering an accurate depiction of "city health".

Table 4. "cityDNA" model description.

\begin{tabular}{|c|c|c|c|c|c|c|}
\hline State & Category & Bond Types of Pairs of Dimensions & cityDNA Sign + & cityDNA Sign - & Level & Risk \\
\hline A & ideal & $3 \times$ PS & $\checkmark$ & & \multirow{13}{*}[\mathrm{A}-\mathrm{J}]{} & \multirow{13}{*}{ [J-A] } \\
\hline $\mathrm{B}+$ & \multirow{3}{*}{ normal } & \multirow{2}{*}{$(2 \times \mathrm{PS}$ and $1 \times \mathrm{PW})$ or $(1 \times \mathrm{PS}$ and $2 \times \mathrm{PW})$} & $\checkmark$ & & & \\
\hline B- & & & & $\checkmark$ & & \\
\hline B & & $3 \times$ PS & & $\checkmark$ & & \\
\hline $\mathrm{C}+$ & \multirow{3}{*}{ abnormal } & $1 \times \mathrm{NW}$ and $(2 \times \mathrm{PS}$ or $2 \times \mathrm{PW}$ or $(1 \times \mathrm{PS}$ and $1 \times \mathrm{PW}))$ & $\checkmark$ & & & \\
\hline $\mathrm{C}-$ & & $1 \times \mathrm{NW}$ and $(2 \times$ PS or $2 \times \mathrm{PW}$ or $(1 \times \mathrm{PS}$ and $1 \times \mathrm{PW}))$ & & $\checkmark$ & & \\
\hline C & & $\begin{array}{c}3 \times \text { PS or } 3 \times \text { PW or }(2 \times \text { PS and } 1 \times \text { PW }) \text { or }(1 \times \text { PS and } \\
2 \times \text { PW })\end{array}$ & & & & \\
\hline $\mathrm{D}+$ & \multirow{6}{*}{ mutated } & \multirow{2}{*}{$1 \times$ NS and $(2 \times$ PS or $2 \times$ PW or $(1 \times$ PS and $1 \times$ PW $))$} & $\checkmark$ & & & \\
\hline D- & & & & $\checkmark$ & & \\
\hline E+ & & \multirow{2}{*}{$(2 \times \mathrm{NW}$ and $1 \times \mathrm{NS})$ or $(1 \times \mathrm{NW}$ and $2 \times \mathrm{NS})$} & $\checkmark$ & & & \\
\hline E- & & & & $\checkmark$ & & \\
\hline $\mathrm{F}+$ & & $\begin{array}{c}3 \times \mathrm{NS} \text { or } 3 \times \mathrm{NW} \text { or }(2 \times \mathrm{NS} \text { and } 1 \times \mathrm{NW}) \text { or }(1 \times \mathrm{NS} \\
\text { and } 2 \times \mathrm{NW})\end{array}$ & \multicolumn{2}{|c|}{$<>$} & & \\
\hline F- & & $3 \times \mathrm{NS}$ & & $\checkmark$ & & \\
\hline
\end{tabular}

The "cityDNA" profile and the "city performance" change over time, depending on changes in KPI values, as does human DNA that changes over time, revealing the state of health of the human body. Monitoring these changes over time will provide an opportunity to measure the maturity of cities in terms of achieving smartness and resilience, as indicators can be compared and conclusions drawn.

\section{6. "cityDNA" Framework Implementation and Verification}

This section provides a brief overview of the development of the "cityDNA" Web service and a case study that exploits this service as part of the experimentation and testing of the proposed framework.

\section{1. "cityDNA" Model Realization as a Web Service}

The design and development of the "cityDNA" Web service was carried out identifying its input, output and effective operation. The proposed Web service is dynamic and expandable, since it offers flexibility and allows the exploitation of data coming from various sources (e.g., open data, UGC, etc.). The proposed Web service is an open architecture software [83], and therefore, its development can be performed by exploiting alternative technologies. The design of the back-end framework, which is the backbone of Web services as it determines their effectiveness, interactions and, finally, their quality, and the front-end framework, which determines the user interface (UI), was carried out 
with the aim of developing a user-friendly service that is scalable and flexible. Taking into account that software development is beyond the scope of this paper, no further technical details are provided for the proposed Web service. However, it is worth describing the custom rule-based data uploader through which users feed the service with data (Figure 3). Well-structured texts in the form of JSON files (.json) are available to the users that want to register their data to produce the "cityDNA" profile on the fly. This format follows rules so that the Web service can consume the input as if the file is from a real-time data source or the file is uploaded by the user as ready to be processed. The establishment of rules, which is based on the ISO 37120 Standard, is necessary to collect and enter in the service only data that are related to KPIs, so that it is feasible to measure city performance and save valuable resources (e.g., memory, money, energy, etc.). The data that the user enters in the service is already in the form of a validated JSON, and only information such as rates and time period to which every rate refers to must be modified by the user. The data is processed as long as the user uploads it, and in case of an error, the system displays informative messages to user. If the data entry process is completed successfully, the user will be able to see the "cityDNA" profile being generated. In addition, the use of APIs that will transfer data from open data platforms is under investigation.

\subsection{Use Case for Model Verification}

A case study on the use of the proposed Web service designed as part of the experiment to test and verify the proposed "cityDNA" model is presented herein. Specifically, the case study concerns the synthesis of ISO KPIs and "cityDNA" profiles through the proposed Web service for the cities of Boston and London. Given that data collection from crowdsourcing activities was not feasible at this early stage of the "cityDNA" framework development, urban data derived from open data platforms (i.e., ANALYSE BOSTON (https:/ / data.bos ton.gov / (accessed on 10 March 2020)), LONDON DATASTORE (https: / data.london.go v.uk / (accessed on 10 March 2020), etc.) were utilized. Thus, after a relevant research on the available urban data, the cities of London and Boston were selected for our case study. These cities, being two representative examples for America and Europe respectively, are considered among the smartest cities in the world, have rich and up-to-date open data platforms, as well as their data are suitable for the synthesis of ISO KPIs since they were certified by WWCD [26]. The indicators selected for each of the six dimensions and data for the reference cities and the cities of London and Boston are presented in Table 5.

Table 5. Data and KPIs for synthesis of "cityDNA" profile (Sources: [s1-s15] in Appendix A).

\begin{tabular}{|c|c|c|c|c|c|c|c|}
\hline \multirow{2}{*}{$\begin{array}{c}\text { City } \\
\text { Dimension }\end{array}$} & \multirow{2}{*}{ KPI } & \multirow{2}{*}{ Reference City + } & \multirow{2}{*}{ Reference City - } & \multicolumn{2}{|c|}{ Boston } & \multicolumn{2}{|c|}{ London } \\
\hline & & & & Previous & Last & Previous & Last \\
\hline & 5.1-Unemployment & Luxembourg & Kinshasa & & & & \\
\hline Economy & $\begin{array}{l}\text { // www.statista.com } \\
\text { /statistics/381057/u } \\
\text { nemployment-rate-i } \\
\text { n-luxembourg/ } \\
\text { (accessed on 20 July } \\
\text { 2020)) }\end{array}$ & $5.41 \%$ & $10.4 \%$ & $2.3 \%[\mathrm{~s} 1]$ & $2.0 \%[\mathrm{~s} 1]$ & $4.3 \%[\mathrm{~s} 2]$ & $4.7 \%[\mathrm{~s} 2]$ \\
\hline & 10.4-Voter & Brussels & Santiago & & & & \\
\hline Governance & $\begin{array}{l}\text { municipal election } \\
\text { (https: } \\
\text { / / worldpopulationr } \\
\text { eview.com/country- } \\
\text { rankings/voter-tur } \\
\text { nout-by-country } \\
\text { (accessed on } 20 \text { July } \\
\text { 2020)) }\end{array}$ & $83.5 \%$ & $48.0 \%$ & $28.0 \%[\mathrm{~s} 3]$ & $16.5 \%$ [s4] & $70.1 \%$ [s5] & $53.8 \%$ [s6] \\
\hline
\end{tabular}


Table 5. Cont

\begin{tabular}{|c|c|c|c|c|c|c|c|}
\hline \multirow{2}{*}{$\begin{array}{c}\text { City } \\
\text { Dimension }\end{array}$} & \multirow{2}{*}{ KPI } & \multirow{2}{*}{ Reference City + } & \multirow{2}{*}{ Reference City - } & \multicolumn{2}{|c|}{ Boston } & \multicolumn{2}{|c|}{ London } \\
\hline & & & & Previous & Last & Previous & Last \\
\hline People & $\begin{array}{l}\text { 6.2-Percentage of } \\
\text { students completing } \\
\text { primary education }\end{array}$ & $\begin{array}{c}\text { Praia } \\
\text { (https://tradingeco } \\
\text { nomics.com/cape-ve } \\
\text { rde/net-intake-rate- } \\
\text { in-grade-1-male-pe } \\
\text { rcent-of-official-scho } \\
\text { ol-age-population- } \\
\text { wb-data.html } \\
\text { (accessed on } 20 \text { July } \\
2020 \text { )) } \\
97.48 \%\end{array}$ & $\begin{array}{c}\text { Harare (http: } \\
\text { // mopse.co.zw/site } \\
\text { s/default/files/pub } \\
\text { lic/downloads/An } \\
\text { nual\%20Education } \\
\% 20 \text { Statistics\%20Re } \\
\text { port } \% 202018 . p d f \\
\text { (accessed on 20 July } \\
\text { 2020)) } \\
37.69 \%\end{array}$ & $54.2 \%$ [s7] & $76.4 \%$ [s7] & $99.9 \%$ [s8] & $99.9 \%[\mathrm{~s} 8]$ \\
\hline Environment & $\begin{array}{c}\text { 23.5-Total water } \\
\text { consumption per } \\
\text { capita (https://www. } \\
\text { statista.com/statistic } \\
\text { s/263156/water-con } \\
\text { sumption-in-select } \\
\text { ed-countries/ } \\
\text { (accessed on 20 July } \\
\text { 2020)) (liters/day) }\end{array}$ & Kampala & Buenos Aires & 302 [s9] & 246 [s10] & 154 [s11] & 164 [s12] \\
\hline Living & $\begin{array}{l}\text { 11.1-Average life } \\
\text { expectancy }\end{array}$ & $\begin{array}{c}\text { Bern (https://www. } \\
\text { statista.com/statistic } \\
\text { s/974697/life-expect } \\
\text { ancy-at-birth-in-swi } \\
\text { tzerland-by-gender/ } \\
\text { (accessed on 20 July } \\
2020) \text { ) } \\
85.7\end{array}$ & $\begin{array}{l}\text { Mbanane (https://en } \\
\text {.wikipedia.org/wik } \\
\text { i/List_of_countries_ } \\
\text { by_life_expectancy } \\
\text { (accessed on 20 July } \\
2020)) \\
50.9\end{array}$ & 80.2 [s13] & 78.0 [s13] & 82.0 [s14] & 82.6 [s14] \\
\hline Mobility & $\begin{array}{l}\text { 18.1-Number of } \\
\text { Internet connection } \\
\text { per } 100,000 \\
\text { population }\end{array}$ & $\begin{array}{l}\text { Oslo (https:/ / www. } \\
\text { internetworldstats.c } \\
\text { om/top25.htm } \\
\text { (accessed on } 20 \text { July } \\
\text { 2020)) } \\
\\
98.4 \%\end{array}$ & $\begin{array}{c}\text { Tegucigalpa } \\
\text { (https://en.wikiped } \\
\text { ia.org/wiki/List_of_- } \\
\text { countries_by_numbe } \\
\text { r_of_Internet_users } \\
\text { (accessed on 20 July } \\
2020) \text { ) } \\
32.3 \%\end{array}$ & $93.0 \%$ & $95.0 \%$ & $91.0 \%$ [s15] & $93.0 \%$ [s15] \\
\hline
\end{tabular}

The following steps are taken by the user (SSC stakeholder) to create the "cityDNA" profile of a city through the Web service:

1. Enter the name of the preferred city (e.g., Boston) and press the "Start the process of discovering" button (Figure 6).

2. Select the preferred pairs of dimensions through an easy-to-use "drag and drop" menu that includes the six city dimensions (Figure 7). KPIs of ISO 37120:2018 were set and are available for each of the six dimensions. These indicators are displayed by selecting the pairs of dimensions, as depicted in Figure 7. It is noted that due to the complexity due to the existence of many indicators per dimension, this version supports the selection of only one KPI per dimension.

3. Select the preferred KPI for each dimension (e.g., 5.1, 10.4) and upload a JSON file or create the JSON file by filling in the appropriate fields in the content box of the Web service. The KPI selection and the data entry for the dimensions of economy and governance are presented in Figure 8, while for the rest of the dimensions, are presented in Figures A2 and A3 of Appendix B. The validity of the file or the content that the user uploads to the service is checked by the rules set in the Web service (rule-based uploader) to ensure the synthesis of ISO KPIs.

4. Complete the procedure by pressing a button, entitled "Start Analysis" button. Then, all the necessary calculations are performed and the "cityDNA" profile is generated and visualized (Figure 9). 


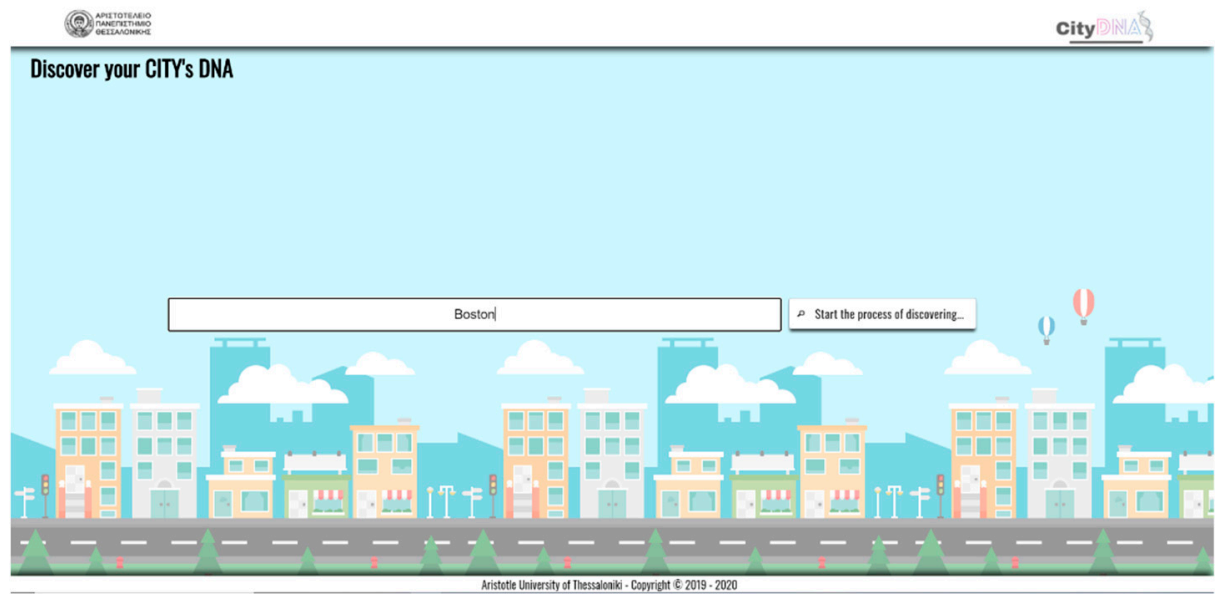

Figure 6. City selection.

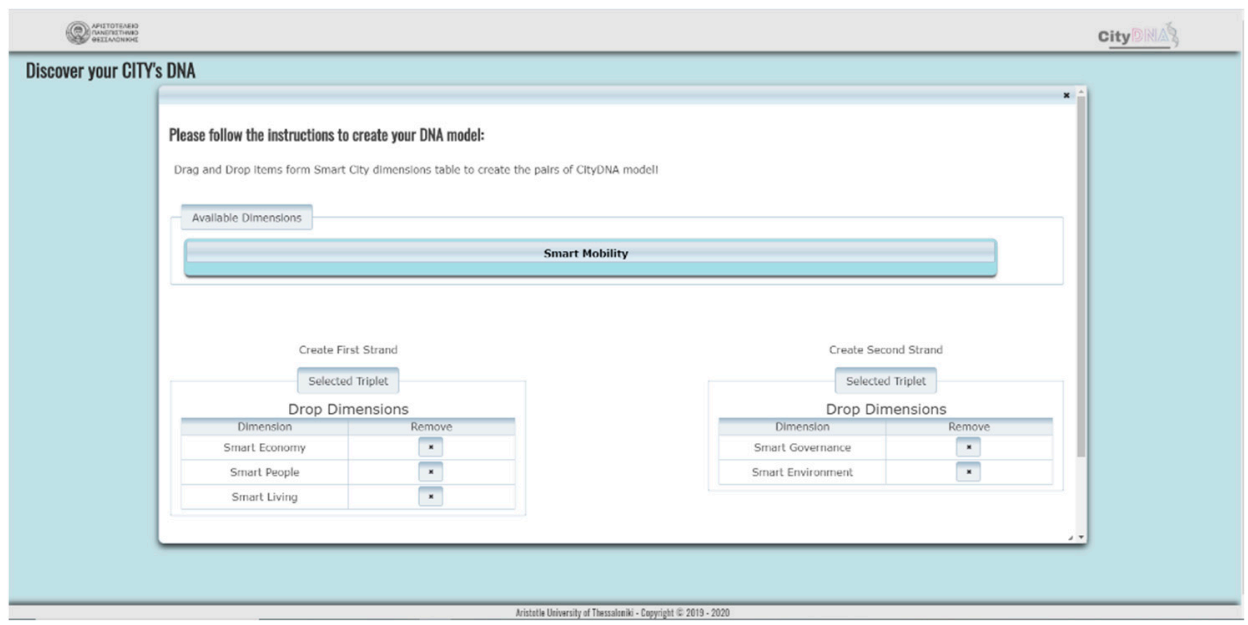

Figure 7. Formation of "cityDNA" strands based on the selected city dimensions.

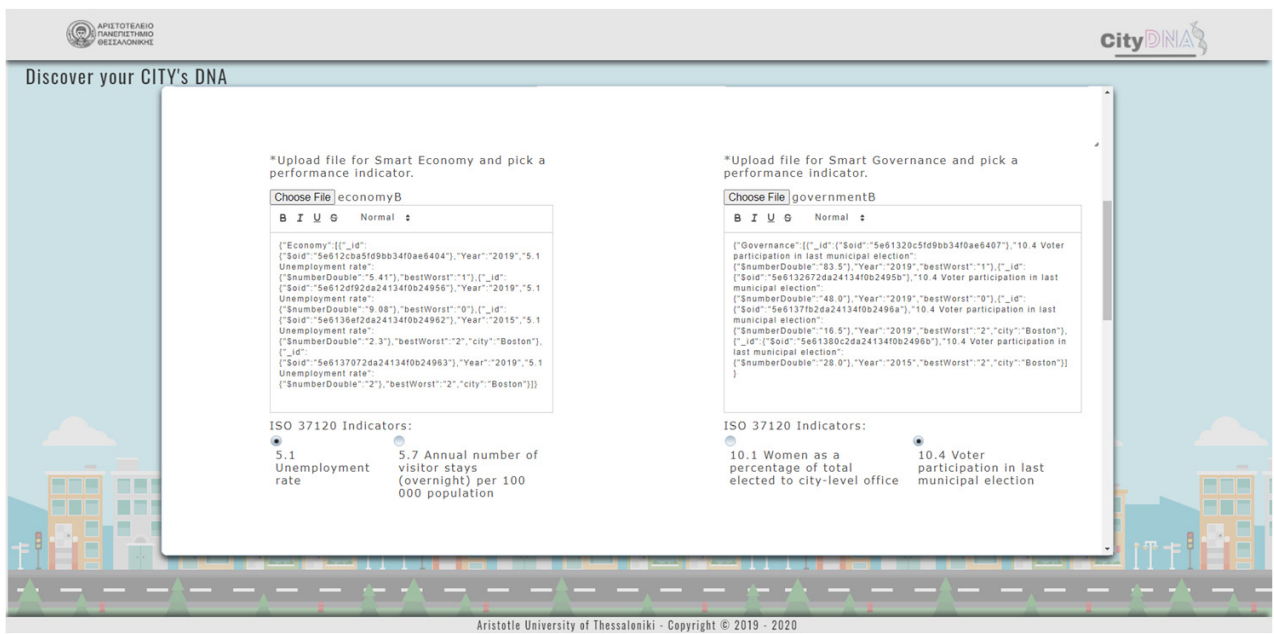

Figure 8. KPIs' selection and data entry for their synthesis. 


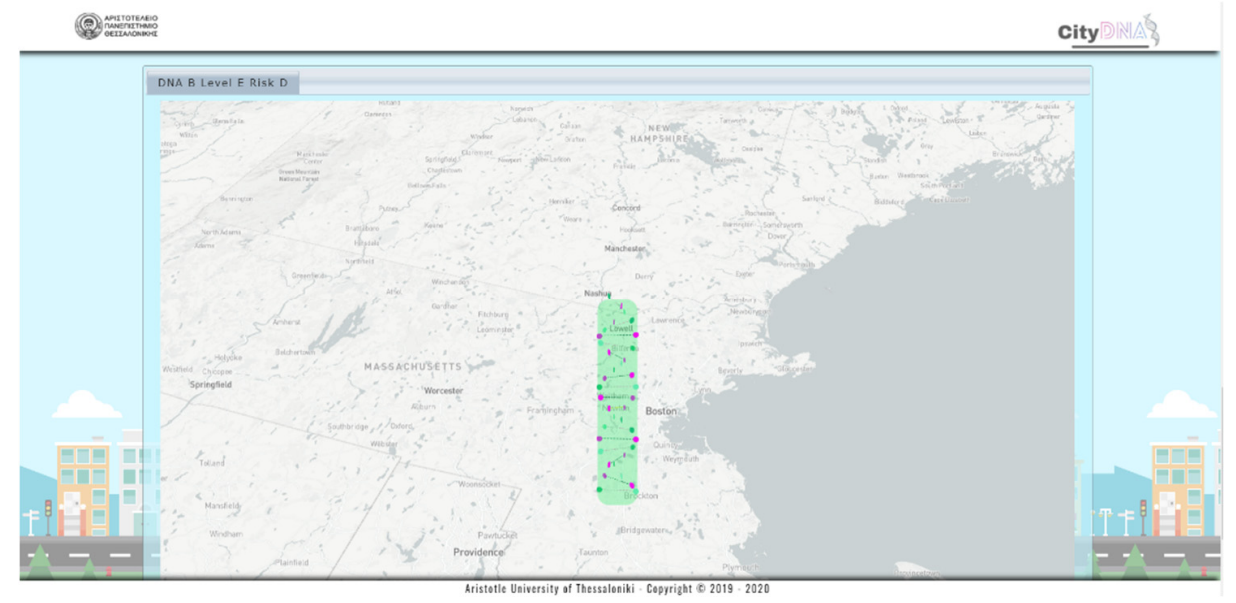

Figure 9. The "cityDNA" of Boston, based on KPIs of ISO 37120:2018.

Thus, the Web service, using the KPIs of Table 5 and data for Boston city, returns the "cityDNA" profile of Boston, that is a snapshot of the city profile which reveals the current "city health" (city performance). The "cityDNA" profile of Boston is characterized as "B" with Level E and Risk D, and falls into the normal category with strong bonds between the dimensions (Table 4). The current city performance is quite satisfactory for Boston, and can be further improved by leveraging the knowledge gained from the Web service and taking appropriate action. It should be noted that the synthesis of a comprehensive city profile via the proposed Web service, which reveals the global performance of the city (city health), requires the exploitation of all KPIs, which are proposed for the six dimensions of the city. Therefore, the generated "cityDNA" profile is expected to be changed and determined by the KPI values, which change over time. In addition, the service returned the evolution of KPI values in the last two years in the form of charts (Figure A4a-d in Appendix B). According to these outcomes, the change in KPI 10.4 (Voter turnout in the last municipal elections) reveals a decrease in voter turnout, which has a negative effect on city performance, while the change in KPI 5.1 (Unemployment Rate) reveals a decrease in the unemployment rate, which has a positive effect on city performance. Moreover, the positive change in KPI 6.2 (Percentage of students completing primary education) and in KPI 23.5 (Total water consumption per capita) led to improved city performance.

Subsequently, the city of London was selected, for which the corresponding KPIs were calculated (Figures A5-A7 in Appendix B). The Web service returned the current "cityDNA" profile, which is characterized as "B" with Level B and Risk A, and falls into the normal category with strong bonds between the dimensions (Figure 10). The current city performance is quite satisfactory for the city of London and can be further improved by leveraging the knowledge gained through the proposed service for improving urban services. Similar to the case of the city of Boston, it is noted that the generated "cityDNA" profile is a snapshot of the London city profile based on the indicators that were used. The synthesis of the comprehensive "cityDNA" profile that reveals the global city performance (city health) requires all the KPIs proposed for the six city dimensions and is as dynamic as most indicators that describe cities. In addition, the service returned the evolution of KPI values in the last two years in the form of charts (Figure A8a-d in Appendix B). According to these outcomes, the changes in KPI 10.4 and KPI 5.1 reveal a decrease in voter turnout and in the unemployment rate that have a negative effect on city performance. In addition, KPI 6.2 remains unchanged, while KPI 23.5 shows an increase that leads to the deterioration of the performance of the city. 


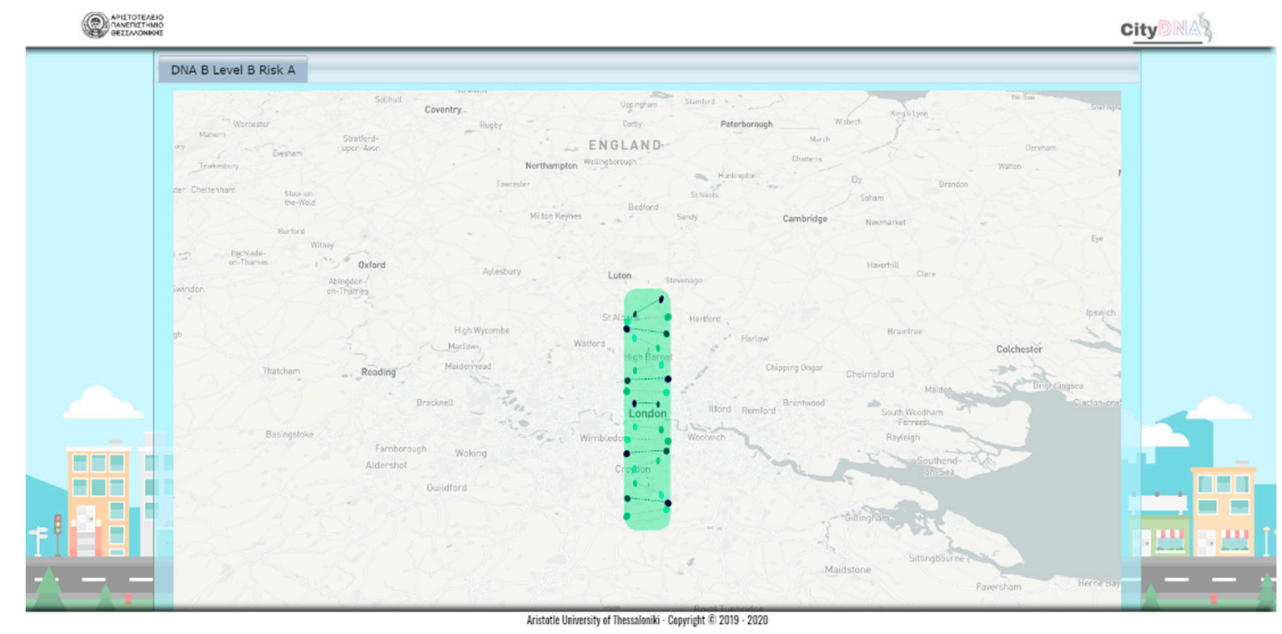

Figure 10. The "cityDNA" of London, based on KPIs of ISO 37120:2018.

Therefore, the profiles of both cities are healthy, as evidenced by the positions of these cities in the recent rankings of SC [84]. The synthesis of the "cityDNA" profile through the proposed service is feasible for each city as long as data is available. It should be noted that the proposed "cityDNA" framework and the corresponding Web service are in the experimental and testing phase, and the capabilities for its improvement and upgrade are being investigated. Their design and development began with common assumptions derived from the use of existing literature, ISO standards for cities and archival data from open data platforms to explore the feasibility of urban data and indicators' exploitation for city profile synthesis and measurement of city performance. Although the proposed "cityDNA" framework includes the exploitation of various urban data sources such as IoT, crowdsourcing, etc., aiming at citizen engagement, only open data was used due to a lack of resources. Some new features that are being explored in the context of improving the proposed service are the following:

- Exploitation of data retrieved from various data sources, some of which will provide real-time data, will lead to the extraction of impartial and updated KPIs, and consequently to the synthesis of a comprehensive and representative "cityDNA" profile that will evolve over time.

- Design and development of algorithms for the data and KPI analysis and forecasting that will be integrated in the proposed service aiming at real-time data exploitation, maintenance forecasting and urban planning facilitating.

- The presentation and comparison of "cityDNA" profiles for two or more cities in a single Web page. This feature, which will facilitate the benchmarking of cities, is expected to help researchers and local authorities to draw conclusions, to seek for best practices and to improve city performance.

- Experimentation with the use of other standards for cities such as ITU standards and comparing them with the ISO standards aiming to investigate and identify similarities and differences.

\section{Proof-of-Concept: Exploring the cityDNA at a Smart City Context}

This section includes a PoC scenario designed to demonstrate the feasibility of the proposed "cityDNA" model and to investigate whether crowdsourcing data from a city complaints service can be used to synthesize ISO KPIs. Specifically, a case study is presented, which concerns evidence from Trikala city. Trikala, located in the center of Greece, is a typical medium-sized city that became the first Greek digital city in 2004 and recently entered the list of the 21 top SCs in the world [85]. Trikala, aspiring to become a data prosumer and cultivate its smartness and resilience, adopted an architecture that follows the BSI model [86] and consists of the following four layers (Figure 11): 
1. First layer: Physical Environment.

2. Second layer: Telecommunications and Electronics (hard ICT facilities).

3. Third layer: Information Technologies (soft ICT facilities).

4. Fourth layer: Infrastructure-based sectors and service-based sectors (end-users and applications).

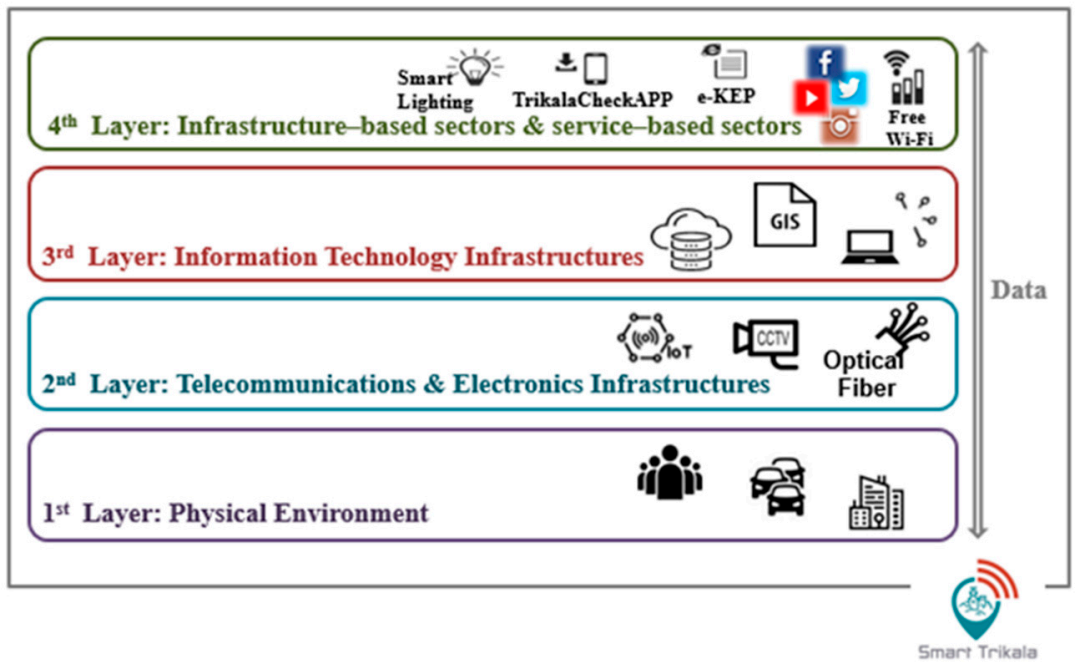

Figure 11. The architecture of Smart Trikala.

The first layer includes the physical environment and the utilities (i.e., people, networks of electricity or water, buildings, vehicles, etc.), while the second layer concerns telecommunications and electronic infrastructures (i.e., IoT, CCTV systems, etc.), which are necessary to collect and store data. The ICT infrastructures (i.e., databases, Cisco Smart and Connected Digital Platform (Kinetic), Geographic Information System (GIS), etc.) are located in the third layer, where the data storage, process and control of all (coming from the second and fourth layers) are carried out. The fourth layer includes all the smart services that have been deployed in the city: such as smart lighting and smart parking systems, e-KEP (citizen self-service center), city's official app (Trikala Check App (https:/ / play.google.com/store/apps/details?id=com.egr.civreq.trikala\&hl=en) (accessed on 30 July 2020)) (i.e., for complaints registration and information retrieval), school app for registration of requests for school units, metro Wi-Fi with a simple social logger, tele-care services, etc., are only some of the available smart services in the testing case. OSN (e.g., Twitter, Facebook, YouTube, etc.,) that are exploited as an alternative channel for connecting the municipality with the citizens are also included in the fourth layer. These layers interact with each other, while the data flow takes place between all the architecture layers.

The development and exploitation of the aforementioned infrastructure led to the achievement of the goal of digitalization of the city, and enabled the creation of the city's open data platform. The Open Data Portal (https: / / data.trikalacity.gr/en (accessed on 30 July 2020)) of Trikala, which is harmonized with the ISO 37120 Standard [26], recognizes the value of free access to data and encourages each to explore data resources and become involved in data production and the development of innovative products that will contribute to further improving the city. In this context, data retrieved from the Open Data Portal was used, aiming at testing and validating the proposed "cityDNA" model. The selection of the KPIs 5.1, 10.4, 6.2, 23.5, 11.1 and 19.1 of ISO 37120 and the entry of the respective data for their synthesis (Figures A9-A11 in Appendix B) returned the "cityDNA" profile of Trikala, which is characterized as " $\mathrm{B}$ " with Level H and Risk C (Figure 12). 


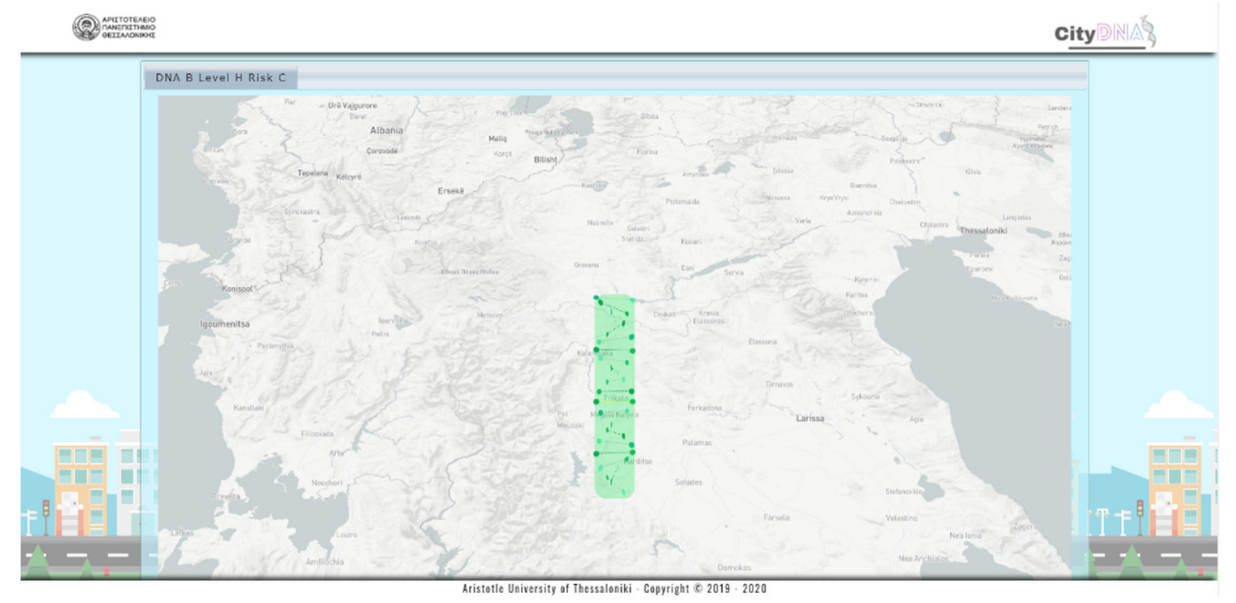

Figure 12. The "cityDNA" of Trikala, based on KPIs of ISO 37120:2018.

The Municipality of Trikala, besides the data published in the Open Data Portal, has data from the complaints registration service that is available to citizens via phone, via the municipal website and via the Trikala Check App. Launched in October 2015, this crowdsourcing service aims to strengthen citizen participation and enhance urban data collection, with the purpose of enhancing the municipal response against documented complaints and in accordance with improving the local quality of life. The data collected by the complaints service revealed that the civic participation increases progressively every year, since the number of citizens' complaints in 2019 were more than double compared to 2016. This fact indicates the gradual increase of the citizens' interest and participation in the improvement of their city, as well as the strengthening of their cooperation with the local authorities. The most important complaint categories, the issues that need to be addressed and the annual number of corresponding complaints are also shown in Table A1 (Appendix C). As it turns out, the citizens, acting as social sensors, informed their municipality about the problems they identified and requested their treatment. The majority of complaints concern public lighting issues, solid waste management, urban cleanliness and streets' maintenance. In addition, citizens register issues regarding public facilities' maintenance, water and sewerage infrastructure and streets' conditions, as well as regarding recycling and unattended animals or other animal issues. These complaints are mainly related to the quality of life, safety and emergency (i.e., protection against floods, storms, fires, etc.).

The availability of the abovementioned data that came from the complaints service led to the idea of their utilization for the synthesis of the "cityDNA" profile of Trikala through the proposed Web service, as this data comes from an alternative data source from the one that was already used previously. Attempting to use this data for the synthesis of some KPIs of ISO 37120, it was found that only data related to solid waste management (i.e., 16.1-16.10) could be used. However, even in this case, the number of complaints about solid waste is not enough, but numbers are required that provide information on the quantity and quality of waste and the citizen participation rates, etc. In addition, the exploitation of this data for the definition of some KPIs of the ISO 37122 and ISO 37123 was investigated. Findings show that the synthesis of KPIs 7.7 (Energy) and 16.4 and 16.6 (Solid Waste) of the ISO 37122 looks reasonable, as long as the municipality provides additional information on the number of the replaced public lights and the quantities of plastic and electrical waste that are collected. Therefore, although the registered complaints data provide valuable knowledge about the city conditions and contribute effectively to the maintenance of urban infrastructure and the improvement of quality of life, this information is not sufficient to calculate the ISO KPIs that measure the city performance.

The PoC scenario, which was presented above, highlighted the practical potential of the "cityDNA" model and led to the extraction of useful findings regarding the urban data 
required for the KPIs population and the ISO standards that measure city performance. By selecting the preferred standard (e.g., ISO standards) and specific KPIs for which data is available, city performance can be measured and "cityDNA" profile can be synthesized using the proposed model. The most appropriate data for the synthesis of these KPIs are aggregated, normalized and static data (i.e., archival data), derived mainly from official agencies such as open data platforms, municipalities, national statistical authorities, etc. On the contrary, in the case where the synthesis of KPIs based on the available data is attempted, difficulties arise. This outcome generates the question that although many cities around the world measure standardized KPIs (e.g., WWCD), and even Trikala does, KPIs are not fed dynamically and smart services are not KPI-oriented. If this observation is true, as it is for the case of Trikala, an interrelation analysis has to be carefully performed, and probably be different for each city.

Data collected by crowdsourcing processes such as the complaints registration service are useful for cities for enhancing service performance and citizen satisfaction. For instance, the complaints registration service in Trikala decreased the response time of the municipal services from 6 months to 10 days to serve citizens' requests [5]. However, the purpose of use and the urban data features (i.e., volume, velocity, variety, veracity, value, integrity, correlation, etc.) that determine the quality of the results of the analysis should be determined in advance so that crowdsourcing activities can be properly planned and yield greater benefits [87]. Additionally, with regard to the existing standards and focusing on the ISO Standards used in this paper, it was found that there are restrictions on the exploitation of the data, and it is not possible to apply them in all cities, since each city has different needs and SSC policies. In particular, the proposed KPIs focus on specific urban services and their synthesis requires the existence of processed data by IoT or official organizations. Nevertheless, these requirements do not meet reality, since many cities do not have infrastructure for data collection, and the exploitation of data from crowdsourcing that offers the benefits previously discussed is not promoted. Therefore, the effective use of KPIs requires the revision of city standards to meet the needs and infrastructure of cities and to highlight their vibrancy.

\section{Conclusions and Future Work}

This paper deals with the demand for KPI interrelation and dynamic feeds to contribute to the fulfilment of SSC promise in terms of instant information on the city performance and decision-making. For this purpose, a novel framework was proposed that generates and visualizes the city profile and provides valuable information on the city performance (city health), through the exploitation of open urban data, in combination with the ISO 37120 KPIs. The idea for this framework came from the combination of the revised version of the "cityDNA" framework [29] with the ISO 37120, which was developed to steer and measure the city performance. The revisited "cityDNA" framework aspires to lay the foundations both for the registration of KPI-driven urban data, which is necessary for the synthesis of KPIs, and their interrelations, with the purposes of shaping SSC profile and facilitating city monitoring and policy-making. Moreover, this framework, along with a Web service, aims to highlight the value of crowdsourcing in urban data production and empower civil participation, and to reveal the weaknesses and the need for a partial revision of the ISO standards for cities, so that KPI synthesis will be feasible and the profile of the city will reflect its vibrancy.

Initially, the need for urban transformation and the concepts of SC and RC were discussed. Next, the important role of KPI-driven urban data and crowdsourcing in urban transformation and the related challenges that city managers have to face in order to take full advantage of them were analyzed. Additionally, the recent urban standardization efforts for urban transformation and benchmarking as well as the city standards proposed by ISO [22] were discussed. Subsequently, the design and implementation of the proposed framework and Web service were presented and a case study involving the cities of Boston and London was conducted for testing and validation. The exploitation of the 
Web service for the selected ISO KPIs and the corresponding open data, returned as a result the "cityDNA" profiles of Boston and London, which reveal their city performance (city health). These profiles verify the reputation and quality of life of these cities, while also highlighting the capabilities of their improvement to SSC stakeholders. It should be noted that the "cityDNA" profile can be changed both with the addition or selection of other KPIs, as well as with the change of KPIs over time. The use of additional KPIs will lead to the synthesis of a more comprehensive "cityDNA" that will better reflect the city performance, while the change of KPIs over time will allow the measurement of SC maturity. Finally, a PoC scenario is presented regarding the city of Trikala, in order to investigate the feasibility of the synthesis of KPIs and the city profile from data that are KPI-driven. The findings revealed that KPI synthesis is feasible, when open KPI-driven data such as those for London and Boston are used. However, in the case where the data comes from a crowdsourcing activity, such as a complaints service, then the KPI synthesis is difficult because the collected data may not be relevant to the indicators. Therefore, when a crowdsourcing activity is planned, KPIs to be measured and the data to be collected for this purpose should be specified.

The limitations that emerged during the design and development of the "cityDNA" model are mainly related to the availability and appropriateness of urban data. Ideally, the development of a model that presents, synthesizes and visualizes the city health in real time requires the exploitation of data streams to provide information about all the dimensions and the services included in them. Since at present no such option is provided, periodic (annual) data from open platforms were used, resulting in the city profiles being static rather than in real-time. In addition, there are no data available for the synthesis of all KPIs, while citizen participation in data production and exploitation of OSN data are limited, and in many cases impossible. Moreover, there are no historical data for all cities to allow them to be compared and used as reference cities, and therefore, the reference countries were used for comparing and determining the dimension's sign in our model. The complex ecosystem of SSC also brought limitations to the design and development of the proposed model, since the ideal "cityDNA" model should visualize the global city profile that includes all KPIs of all city dimensions. However, data retrieval for all KPIs and the correlation between them for the synthesis of "cityDNA" was not possible in this initial version of the model. Thus, in this experimental version, six KPIs were used, each of which corresponds to a smart dimension, while the model is expected to be expanded to include more KPIs and become more comprehensive.

Since "cityDNA" is a promising framework with a great potential, our future thoughts are focused on optimizing the "cityDNA" model and enriching the Web service with new features, as discussed earlier. In addition, the extension of the "cityDNA" model, to enable the integration of more KPIs for each dimension aiming at providing a comprehensive view of cities' performance, will be investigated. The modeling and implementation of ISO 37153, which will provide the ability to track and monitor the maturity level of cities, are also in our plans. Moreover, the documented outcome from the PoC in Trikala that "smart services are not necessarily KPI-oriented and KPI feed is hard" has to be investigated further, and potential correlation testing has to be performed in SC cases. Suggestions for both the smart service developers and the standardization bodies can be extracted from this investigation. A case study which will utilize the crowdsourcing activities for the collection of urban data to enhance citizen participation is also planned. As part of this, the registration of ISO KPI-driven data in the "cityDNA" Web service will be assigned to the students of the School of Informatics and the issues of personal data protection adopting the General Data Protection Regulation (GDPR) [88] will be investigated. Finally, further extension of the proposed framework through the exploitation of advanced AI techniques for managing and predicting city performance is being considered.

Author Contributions: Conceptualization, V.M., A.M., A.V. and L.G.A.; Data curation, V.M., A.M. and L.G.A.; Funding acquisition, A.V.; Investigation, V.M. and A.M.; Methodology, A.M., A.V., V.M. and L.G.A.; Software, A.M. and V.M.; Supervision, A.V. and V.M.; Visualization, A.M. and V.M.; 
Writing—original draft, V.M.; Writing-review \& editing, V.M., A.V. and L.G.A. All authors have read and agreed to the published version of the manuscript.

Funding: This research has been co-financed by the European Union and Greek national funds through the Operational Program Competitiveness, Entrepreneurship and Innovation, under the call RESEARCH-CREATE-INNOVATE (Project Code: T1EDK-03052).

Acknowledgments: The authors thank the Municipality of Trikala for the provision of urban data.

Conflicts of Interest: The authors declare no conflict of interest.

\section{Appendix A}

Data sources for data of reference countries/cities.

s1. YCHARTS. Boston, MA Unemployment Rate. Available online: https:/ /ycharts.com/ indicators/boston_ma_unemployment_rate (accessed on 25 July 2020).

s2. Office for National Statistics. Unemployment. Available online: https:/ /www.ons.go v.uk/employmentandlabourmarket/peoplenotinwork/unemployment (accessed on 25 July 2020).

s3. Wikipedia. 2019 Boston City Council election. Available online: https:/ / en.wikipedia .org/wiki/2019_Boston_City_Council_election (accessed on 25 July 2020).

s4. GBH. Why Is Voter Turnout in Local Elections So Low? Available online: https://ww w.wgbh.org/news / commentary /2019/09/16/why-is-voter-turnout-in-local-election s-so-low 81 (accessed on 25 July 2020).

s5. UK Parliament. General Election 2017: full results and analysis. Available online: https:/ / commonslibrary.parliament.uk/research-briefings/cbp-7979/ (accessed on 25 July 2020).

s6. UK Parliament. Turnout at elections. Available online: https:/ / commonslibrary.parli ament.uk/research-briefings/cbp-8060/ (accessed on 25 July 2020).

s7. Boston Public School. Available online: https://www.bostonpublicschools.org/do main/238 (accessed on 25 July 2020).

s8. Eurostat. Early childhood and primary education statistics. Available online: https:// ec.europa.eu/eurostat/statistics-explained/index.php/Early_childhood_and_prima ry_education_statistics (accessed on 25 July 2020).

s9. The Boston Globe. Water Consumption. Available online: https://www.bostonglobe. com/metro/regionals / south/2013/07/20/water-use-down-but-water-rates-going / q2FpV3jGRCqmKSy4XeG3QP/story.html (accessed on 25 July 2020).

s10. The Commonwealth of Massachusetts. Policy for Developing Water Needs Forecasts for Public Water Suppliers and Communities and Methodology for Implementation. Available online: https:/ / www.mass.gov/doc/water-resources-commission-policy -on-water-needs-forecasts-for-public-water-suppliers/download (accessed on 25 July 2020).

s11. Mayor of London. The London Plan. Available online: https://www.london.gov.uk/ what-we-do/planning/london-plan/current-london-plan/london-plan-chapter-fiv e-londons-response/pol-14 (accessed on 25 July 2020).

s12. Energy Saving Trust. Water consumption. Available online: https://energysavingtr ust.org.uk/sites / default/ files / reports / AtHomewithWater\%287\%29.pdf (accessed on 25 July 2020).

s13. The Commonwealth of Massachusetts. Life expectancy rises in Massachusetts, breaking with national trend. Available online: https: / / www.mass.gov/news/life-expecta ncy-rises-in-massachusetts-breaking-with-national-trend\#: :text=BOSTON\%20\%E2\% 80\%94\%20The\%20average \%20life \%20expectancy,Americans \%20are \%20expected \%20t o\%20live (accessed on 25 July 2020).

s14. Office for National Statistics. Health state life expectancies, UK: 2016 to 2018. Available online: https: / / www.ons.gov.uk/ (accessed on 25 July 2020).

s15. Office for National Statistics. Internet access-households and individuals, Great Britain: 2019. Available online: https://www.ons.gov.uk/peoplepopulationandco 
mmunity/householdcharacteristics/homeinternetandsocialmediausage/bulletins /i nternetaccesshouseholdsandindividuals/2019 (accessed on 25 July 2020).

\section{Appendix B}

Data entry for the synthesis of ISO 37120:2018 KPIs.

Appendix B.1. Boston City

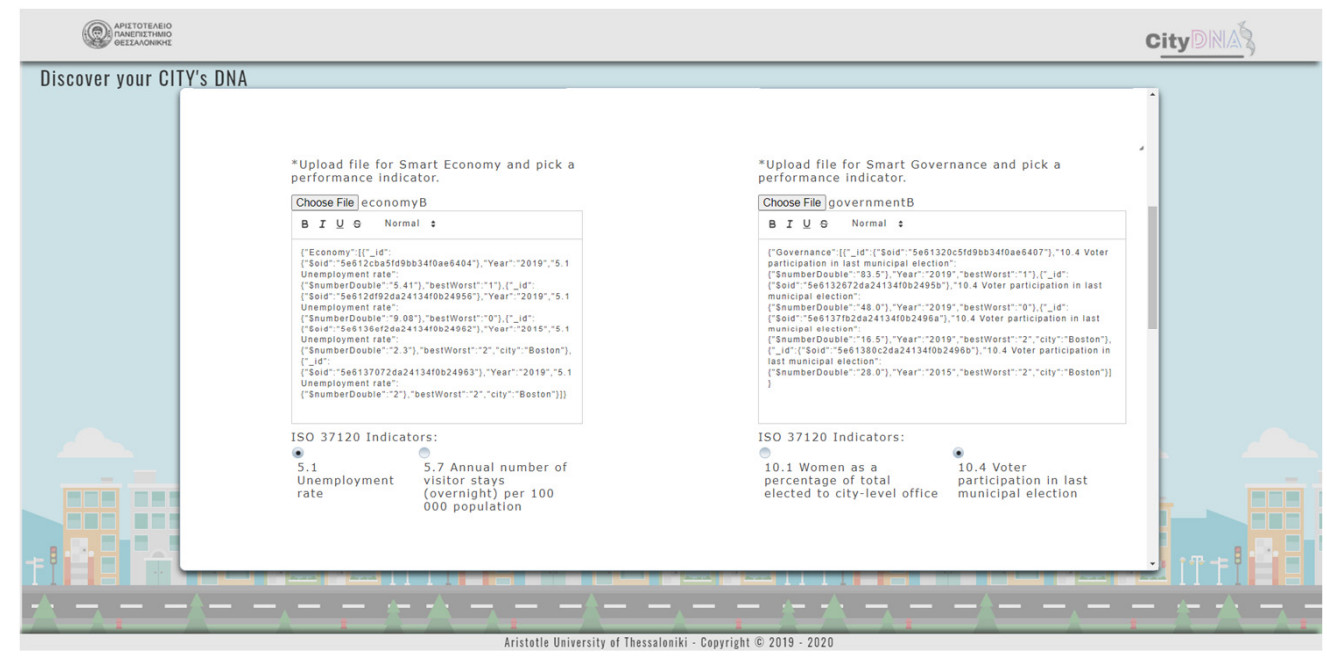

Figure A1. Data for the synthesis of 5.1 and 10.4.

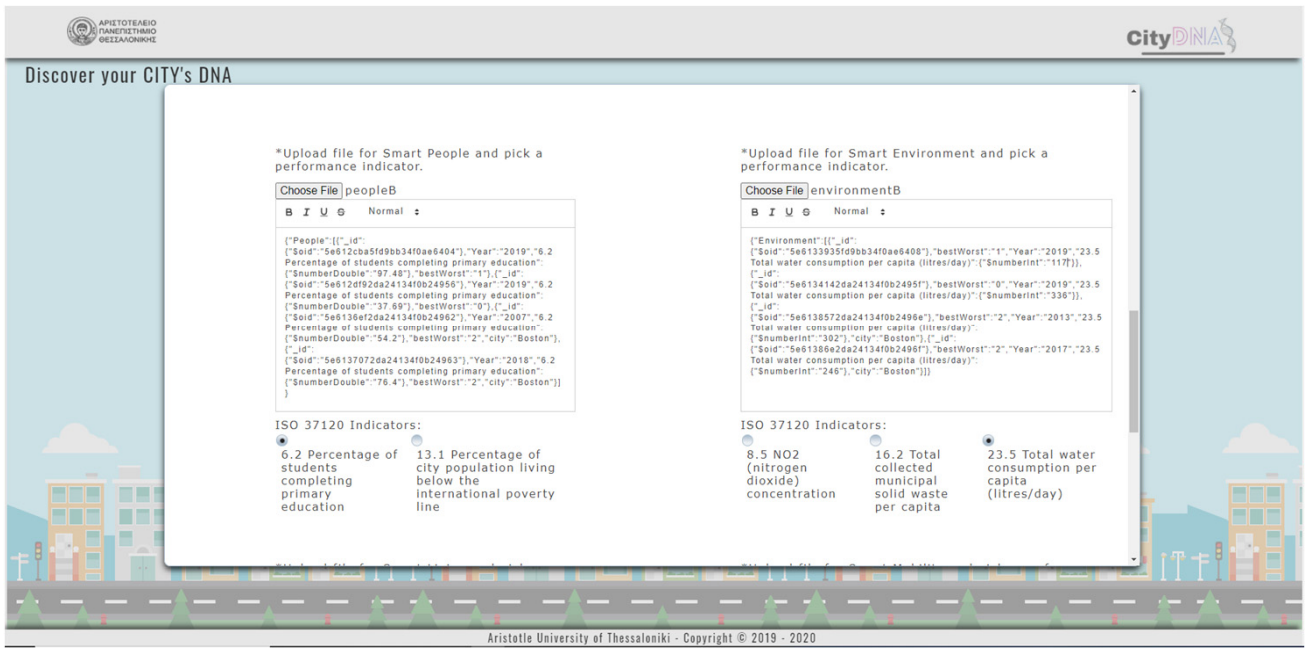

Figure A2. Data for the synthesis of 6.2 and 23.5. 


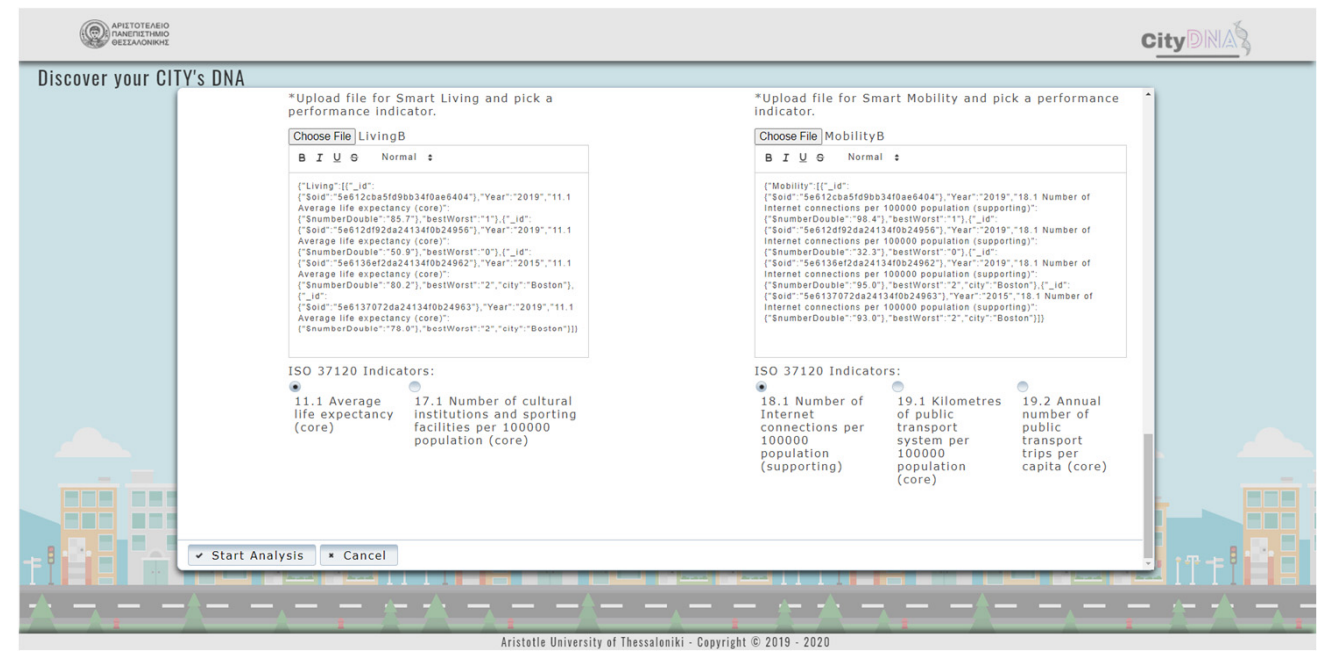

Figure A3. Data for the synthesis of 11.1 and 18.1.

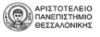

City DNA

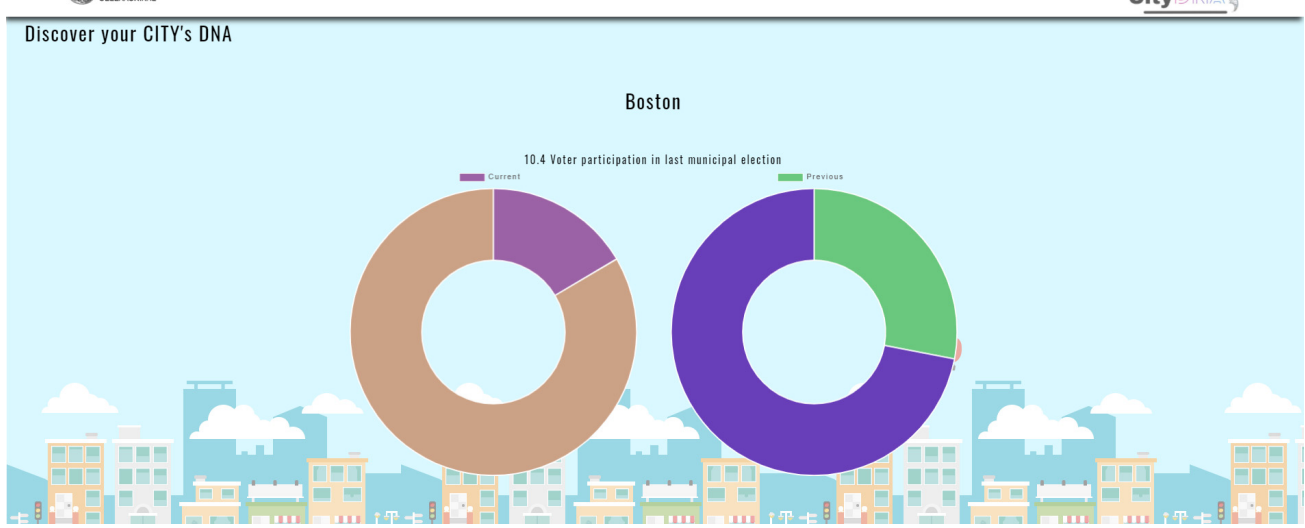

(a) Voter participation in last municipal election

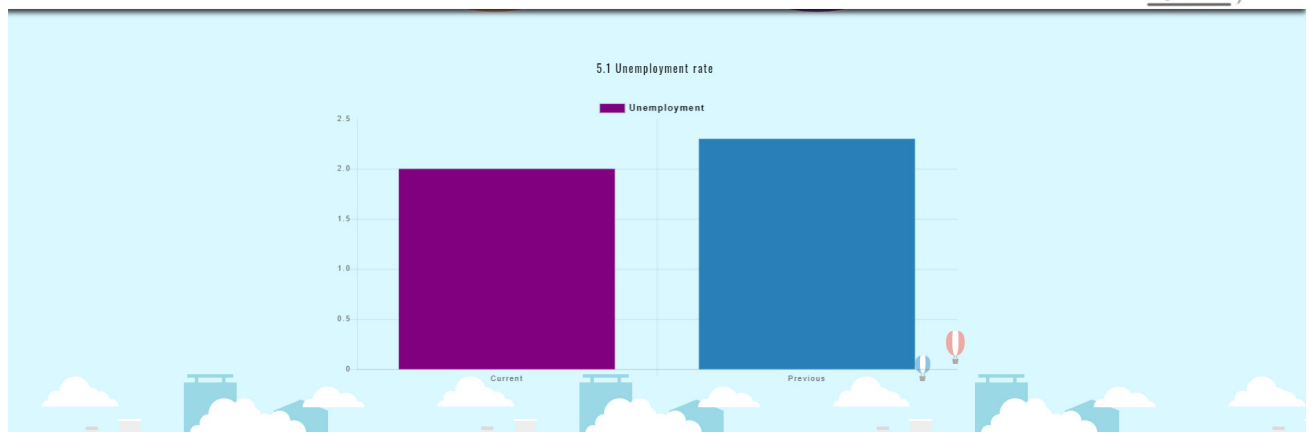

(b) Unemployment rate

Figure A4. Cont. 


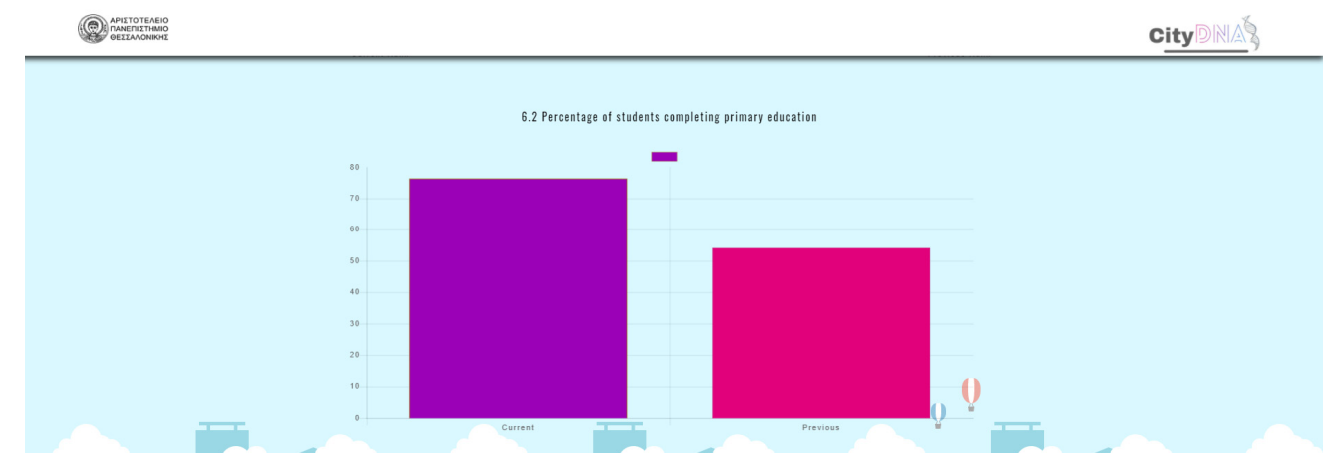

(c) Students completing primary education

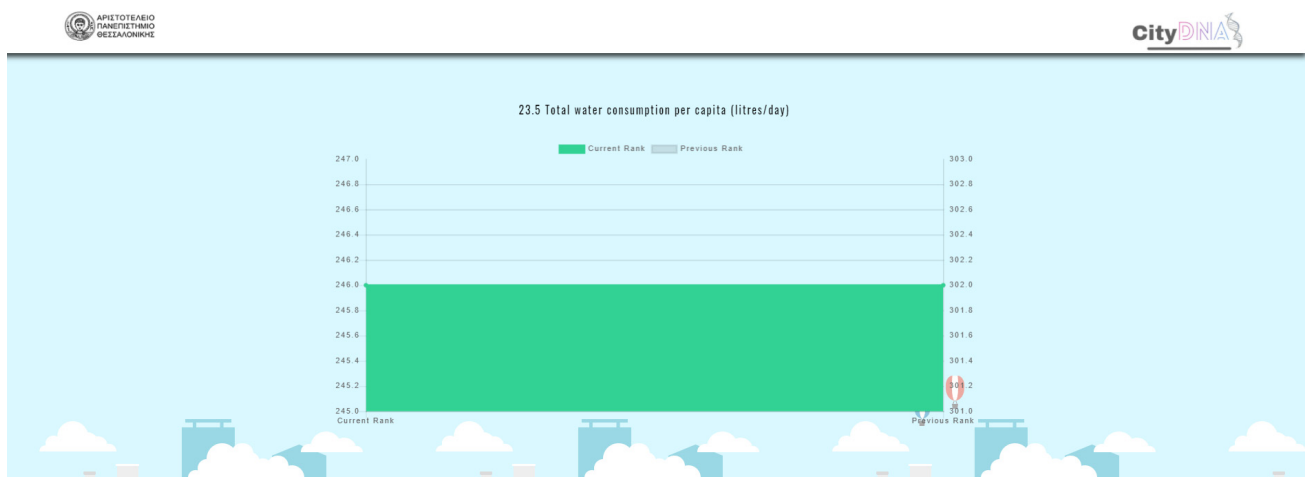

(d) Water consumption per capita

Figure A4. Statistical analysis results for Boston.

Appendix B.2. London City

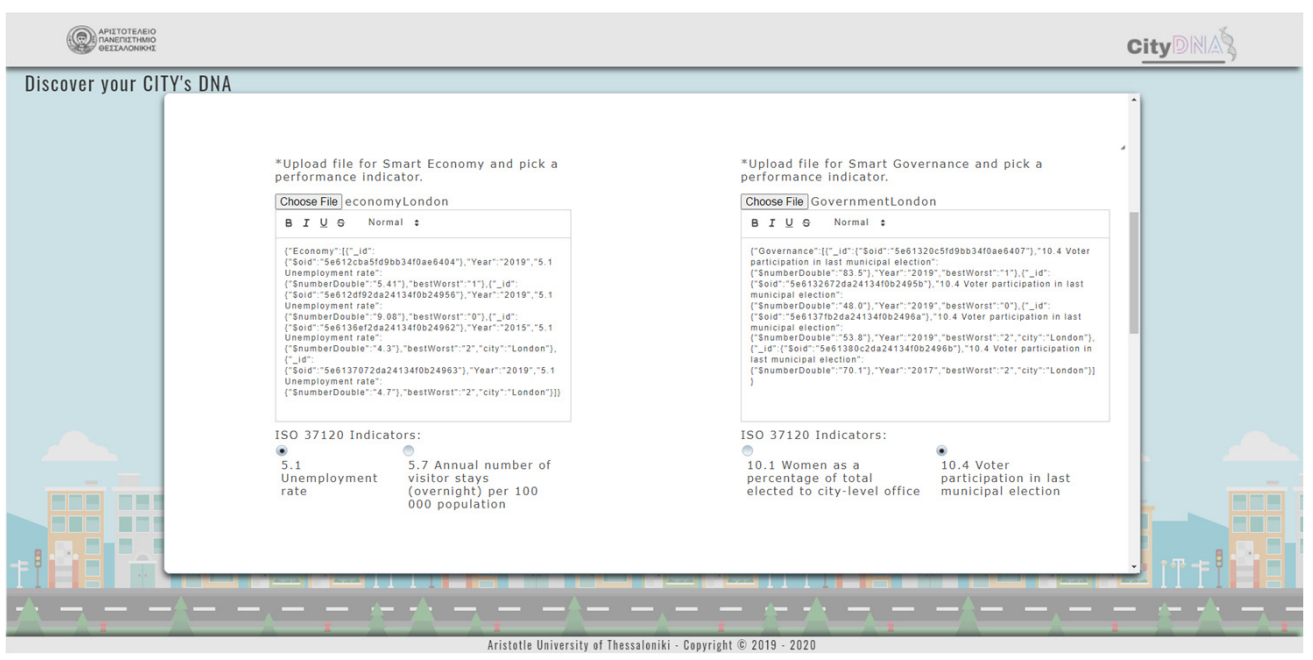

Figure A5. Data for the synthesis of 5.1 and 10.4. 


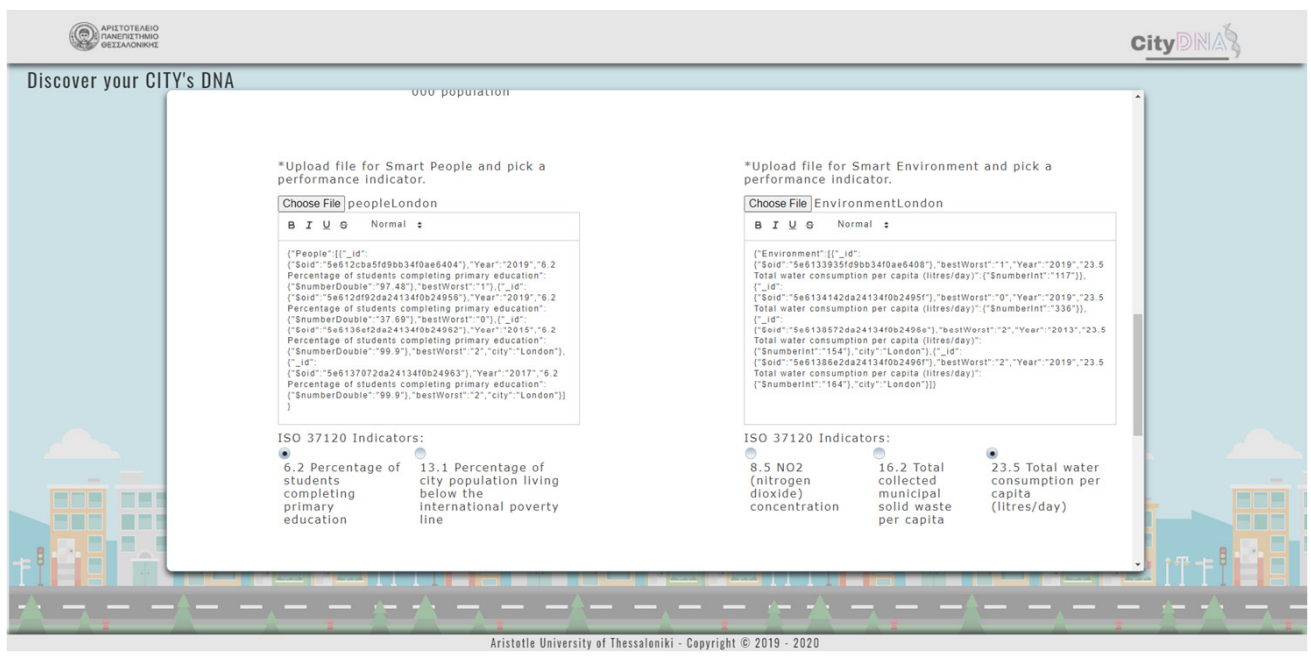

Figure A6. Data for the synthesis of 6.2 and 23.5.

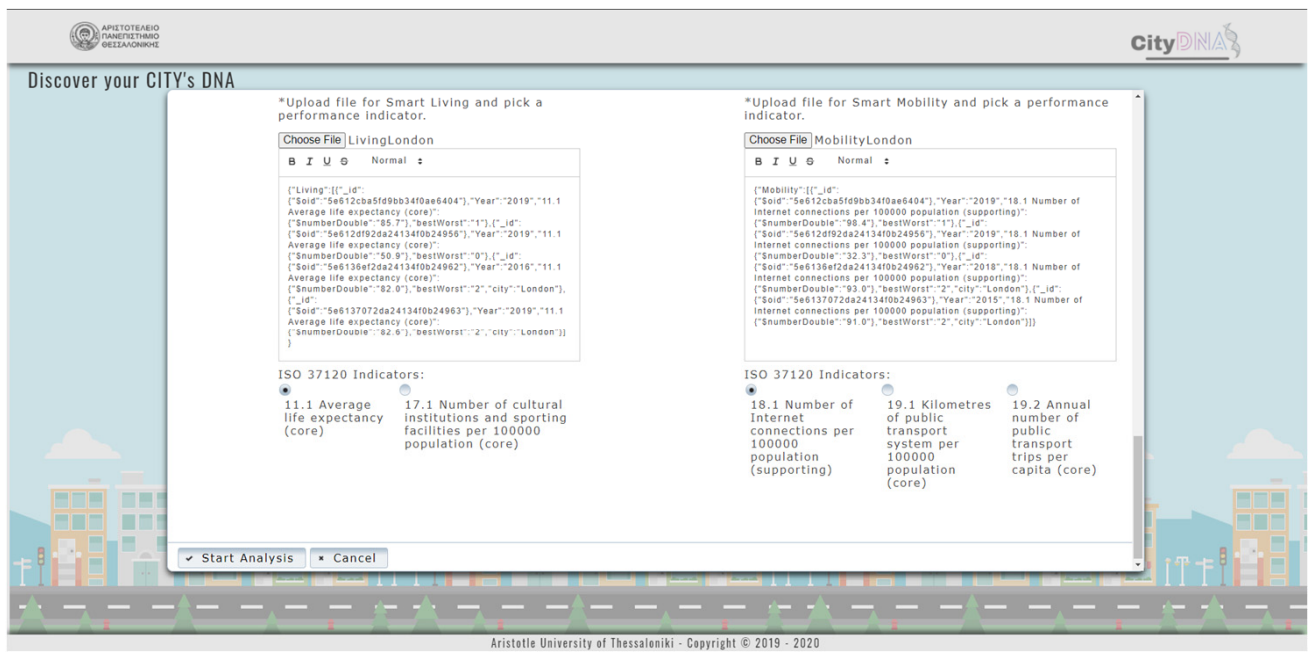

Figure A7. Data for the synthesis of 11.1 and 18.1.

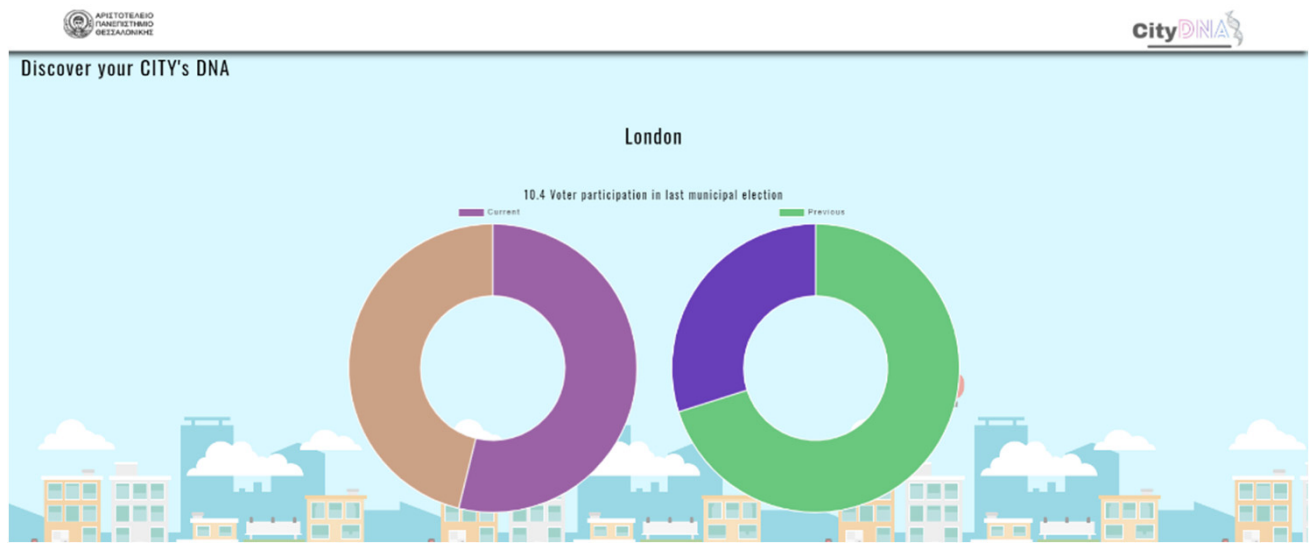

(a) Voter participation in last municipal election

Figure A8. Cont. 


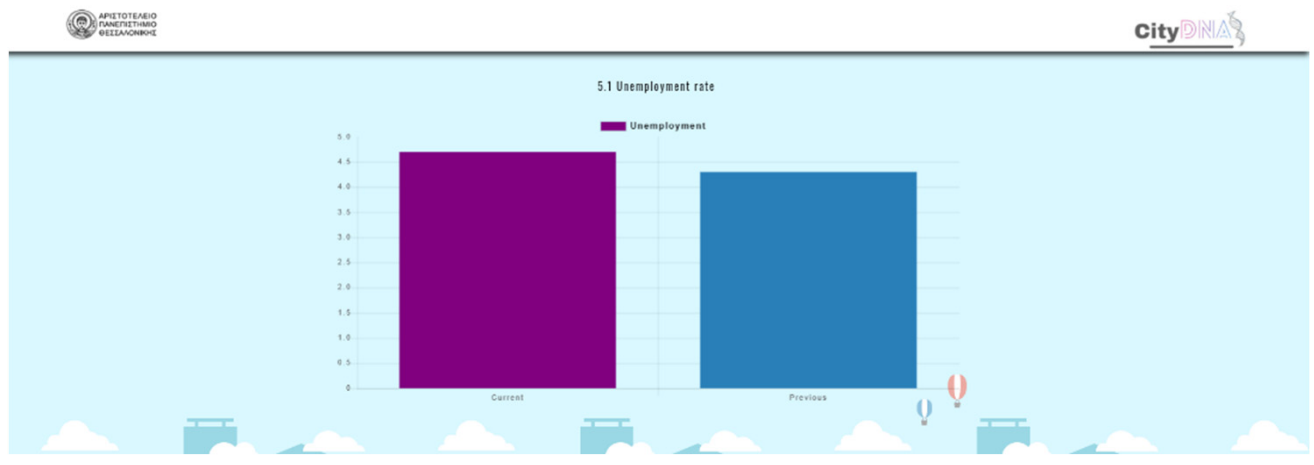

(b) Unemployment rate

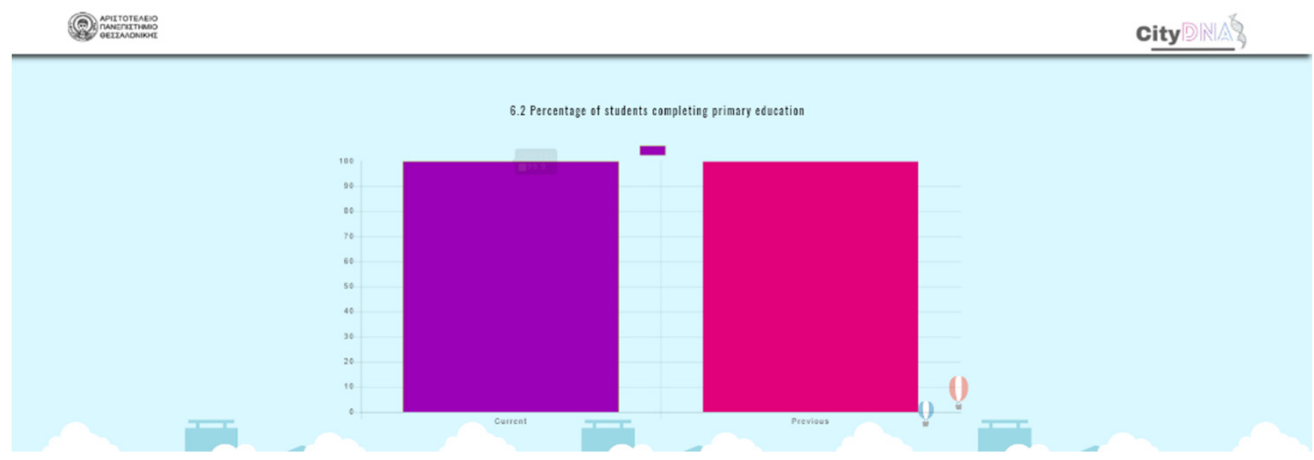

(c) Students completing primary education

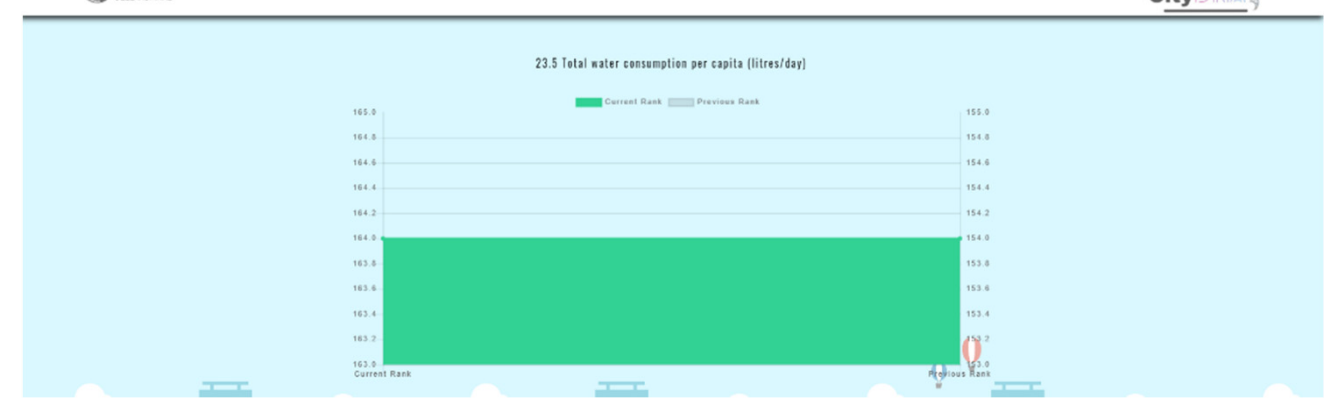

(d) Water consumption per capita

Figure A8. Statistical analysis results for London. 


\section{Appendix B.3. Trikala City}

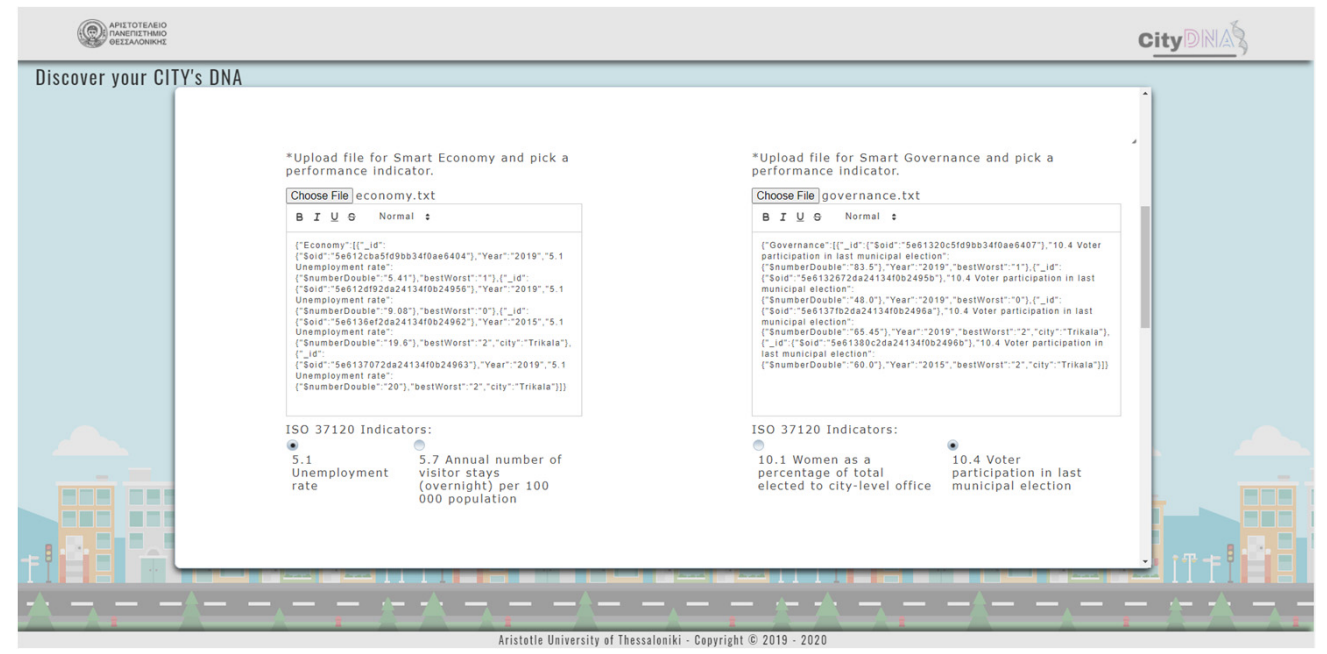

Figure A9. Data for the synthesis of 5.1 and 10.4.

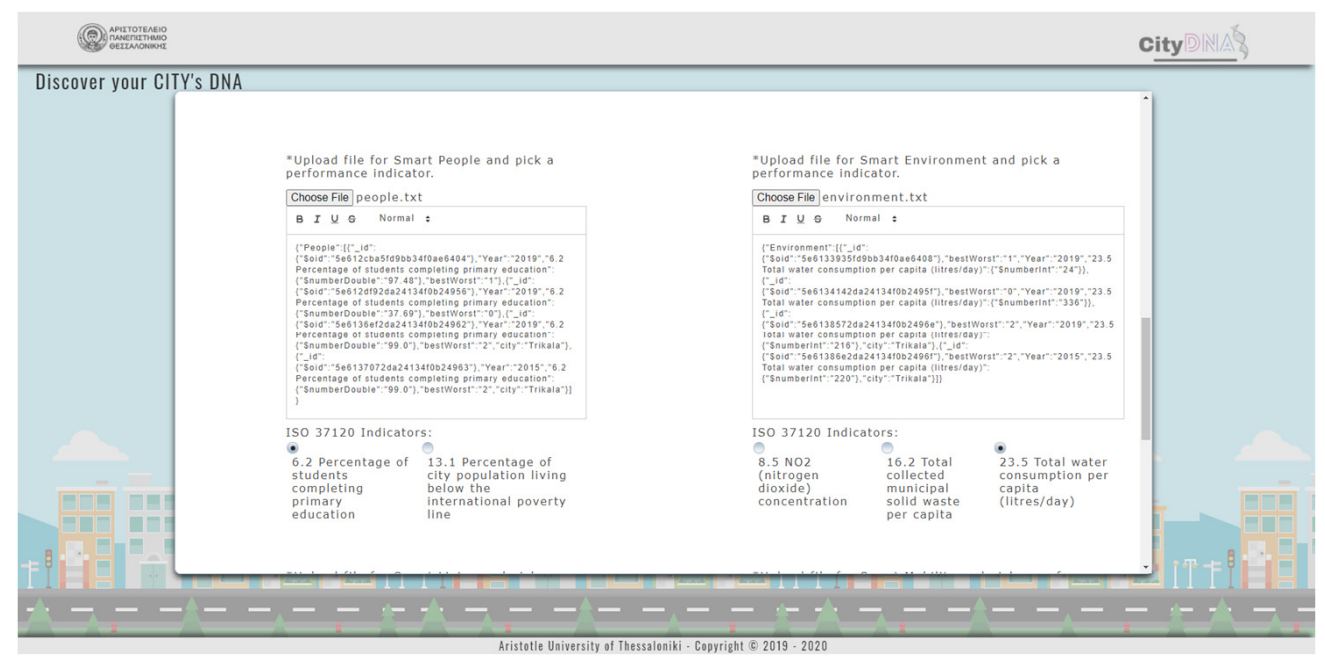

Figure A10. Data for the synthesis of 6.2 and 23.5.

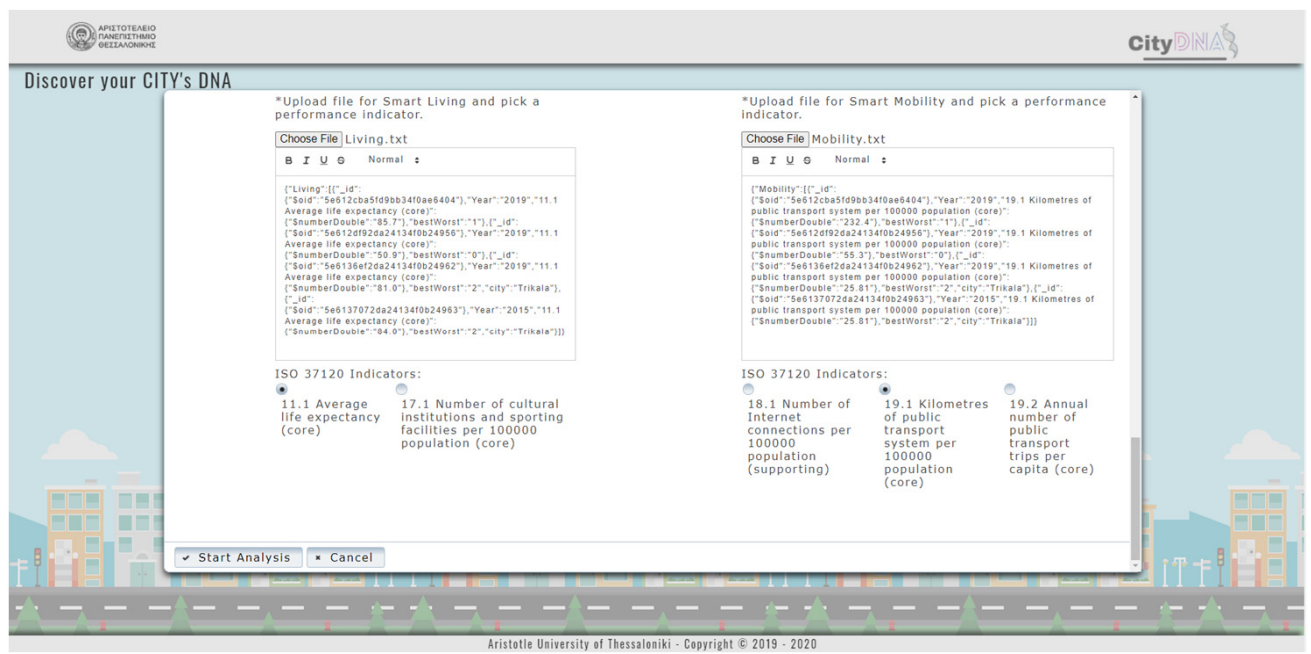

Figure A11. Data for the synthesis of 11.1 and 19.1. 


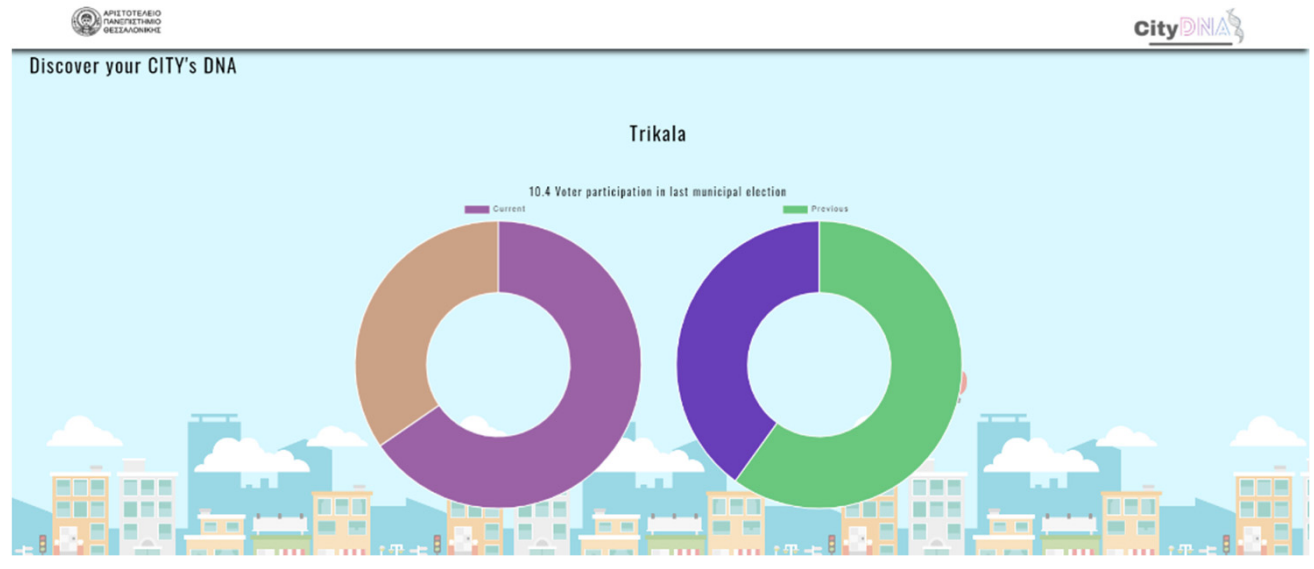

(a) Voter participation in last municipal election

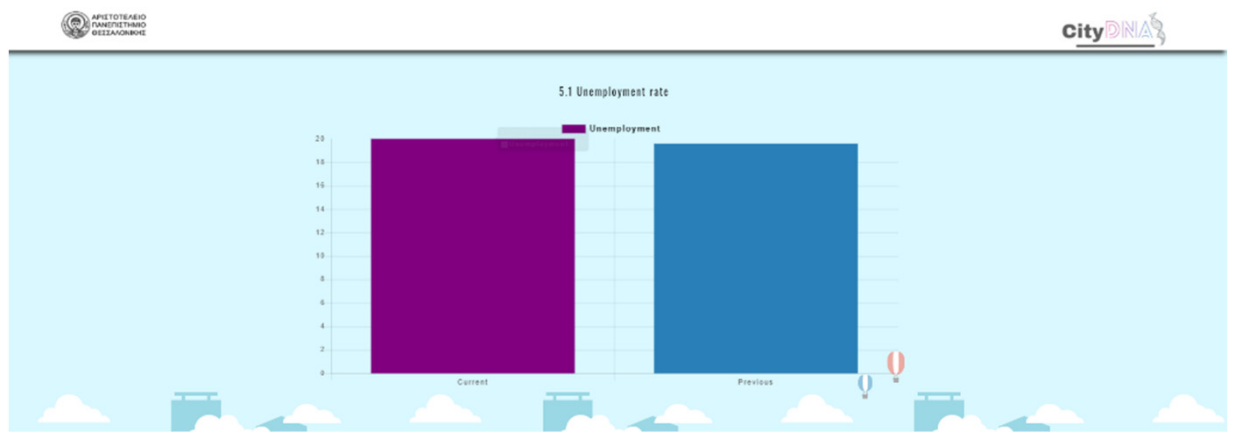

(b) Unemployment rate

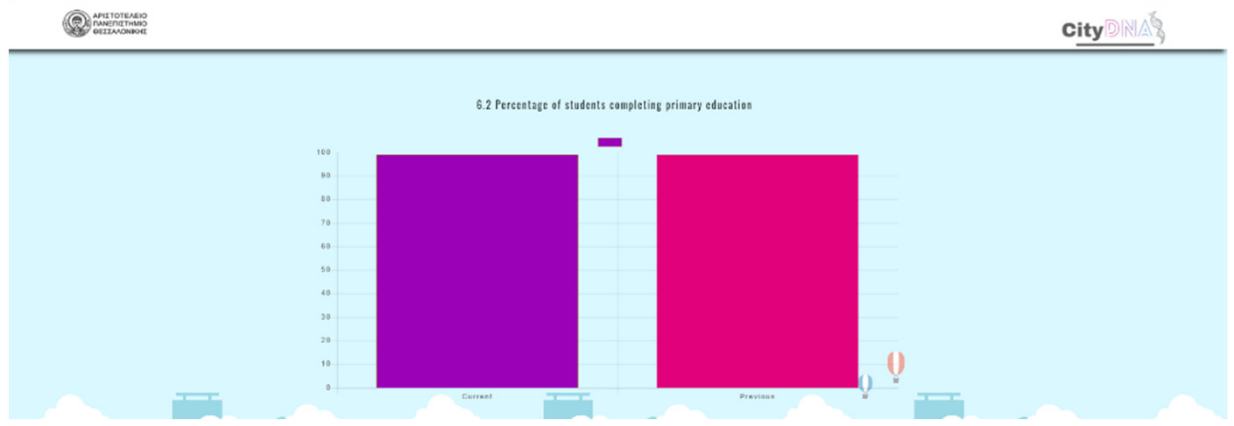

(c) Students completing primary education

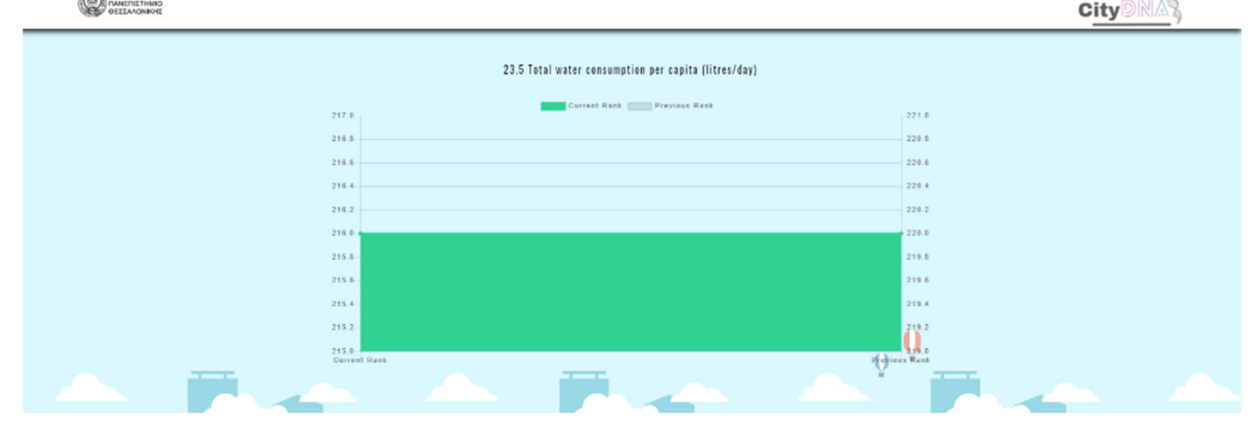

(d) Water consumption per capita

Figure A12. Statistical analysis results for Trikala. 


\section{Appendix C}

Table A1. Categorization of the most important complaints of the citizens of Trikala.

\begin{tabular}{|c|c|c|c|c|c|}
\hline \multirow{2}{*}{ Complaints' Category } & \multirow{2}{*}{ Issues } & \multicolumn{4}{|c|}{ Number of Complaints/Year } \\
\hline & & 2016 & 2017 & 2018 & 2019 \\
\hline \multirow{7}{*}{ Facilities maintenance } & Park maintenance & 0 & 1 & 1 & 3 \\
\hline & Playground maintenance & 2 & 12 & 11 & 57 \\
\hline & School building maintenance & 1 & 5 & 1 & 8 \\
\hline & Square maintenance & 6 & 11 & 5 & 11 \\
\hline & Green maintenance & 67 & 80 & 139 & 89 \\
\hline & Public spaces maintenance & 28 & 117 & 268 & 285 \\
\hline & Total Number of Complaints & 104 & 226 & 425 & 453 \\
\hline \multirow{4}{*}{ Lighting maintenance } & Replacing light bulbs & 1660 & 1468 & 1694 & 2884 \\
\hline & Installation of new lighting fixtures & 6 & 13 & 24 & 24 \\
\hline & General lighting problems & 199 & 257 & 405 & 818 \\
\hline & Total Number of Complaints & 1865 & 1738 & 2123 & 3726 \\
\hline \multirow{6}{*}{ Street maintenance } & General road problems & 29 & 60 & 87 & 105 \\
\hline & Asphalting of roads & 14 & 28 & 38 & 66 \\
\hline & Cement paving/paving of sidewalks & 12 & 29 & 40 & 68 \\
\hline & Road construction problems (potholes) & 94 & 292 & 230 & 264 \\
\hline & Traffic signaling problems & 1 & 46 & 38 & 43 \\
\hline & Total Number of Complaints & 150 & 455 & 433 & 546 \\
\hline \multirow{6}{*}{$\begin{array}{l}\text { Maintenance of water } \\
\text { supply and sewerage } \\
\text { infrastructure }\end{array}$} & General water supply problems & 0 & 9 & 21 & 37 \\
\hline & Water pipe leak & 0 & 12 & 13 & 24 \\
\hline & General drainage problems & 3 & 21 & 21 & 32 \\
\hline & Clogged drainage sump & 10 & 10 & 8 & 21 \\
\hline & Clogged rain well & 15 & 64 & 79 & 167 \\
\hline & Total Number of Complaints & 28 & 116 & 142 & 281 \\
\hline Grounds maintenance & Total Number of Complaints & 437 & 869 & 976 & 2187 \\
\hline \multirow{4}{*}{ Solid waste management } & Collection of bulky waste & 1277 & 1283 & 1274 & 971 \\
\hline & Waste collection & 140 & 123 & 180 & 187 \\
\hline & Waste bin management & 151 & 362 & 261 & 542 \\
\hline & Total Number of Complaints & 1568 & 1768 & 1715 & 1700 \\
\hline \multirow{5}{*}{ Urban cleanliness } & Road cleaning & 213 & 265 & 359 & 360 \\
\hline & Plot cleaning & 6 & 12 & 42 & 395 \\
\hline & Riverbed cleanliness & 4 & 15 & 13 & 12 \\
\hline & General problems of municipal cleanliness & 118 & 111 & 119 & 192 \\
\hline & Total Number of Complaints & 341 & 403 & 533 & 959 \\
\hline \multirow{4}{*}{ Recycling } & Recycling of electrical appliances & 5 & 21 & 10 & 4 \\
\hline & Plastic recycling & 1 & 2 & 1 & 1 \\
\hline & Paper recycling & 5 & 10 & 10 & 9 \\
\hline & Total Number of Complaints & 11 & 33 & 21 & 14 \\
\hline \multirow{3}{*}{ Animals } & Collection of dead animals & 29 & 39 & 73 & 90 \\
\hline & Unattended animals & 4 & 21 & 60 & 219 \\
\hline & Total Number of Complaints & 33 & 60 & 133 & 309 \\
\hline
\end{tabular}

\section{References}

1. Nam, T.; Pardo, T.A. Conceptualizing smart city with dimensions of technology, people, and institutions. In Proceedings of the 12th Annual International Digital Government Research Conference: Digital Government Innovation in Challenging Times, College Park, MA, USA, 12-15 June 2011.

2. Batty, M.; Axhausen, K.W.; Giannotti, F.; Pozdnoukhov, A.; Bazzani, A.; Wachowicz, M.; Ouzounis, G.; Portugali, Y. Smart cities of the future. Eur. Phys. J. Spec. Top. 2012, 214, 481-518. [CrossRef]

3. Anthopoulos, L.G. Understanding Smart Cities: A Tool for Smart Government or an Industrial Trick? Springer International Publishing: Cham, Switzerland, 2017.

4. Moustaka, V.; Vakali, A.; Anthopoulos, L.G. A Systematic Review for Smart City Data Analytics. ACM Comput. Surv. 2019, 51, 1-41. [CrossRef]

5. Anthopoulos, L.G. (Ed.) Smart City Emergence: Cases from around the World; Transportation and Smart Cities Book Series; Elsevier: New York, NY, USA, 2019.

6. Bellini, E.; Ceravolo, P.; Nesi, P. Quantify resilience enhancement of UTS through exploiting connect community and internet of everything emerging technologies. ACM Trans. Internet Technol. 2017, 9, 39. 
7. Pramanik, M.I.; Lau, R.Y.; Demirkan, H.; Azad, M.A.K. Smart health: Big data enabled health paradigm within smart cities. Expert Syst. Appl. 2017, 87, 370-383. [CrossRef]

8. Li, T. Criminal behavior analysis method based on data mining technology. In Proceedings of the International Conference on Smart City and Systems Engineering (ICSCSE'16), Hunan, China, 25-26 November 2016.

9. Lin, B.; Huangfu, Y.; Lima, N.; Lamb, B.; Cook, D.J. Analyzing the relationship between human behavior and indoor air quality. J. Sens. Actuator Netw. 2017, 6, 13. [CrossRef]

10. Moustaka, V.; Theodosiou, Z.; Vakali, A.; Kounoudes, A.; Anthopoulos, L.G. Enhancing Social Networking in Smart Cities: Privacy and Security Borderlines. Technol. Forecast. Soc. Chang. 2019, 142, 285-300. [CrossRef]

11. Dameri, R.P. Smart City Definition, Goals and Performance. In Smart City Implementation. Progress in IS; Springer International Publishing: Cham, Switzerland, 2017. [CrossRef]

12. Huovila, A.; Bosch, P.; Airaksinen, M. Comparative analysis of standardized indicators for Smart sustainable cities: What indicators and standards to use and when? Cities 2019, 89, 141-153. [CrossRef]

13. Airaksinen, M.; Seppä, I.P.; Huovila, A.; Neumann, H.-M.; Iglar, B.; Bosch, P. Smart city performance measurement framework CITYkeys. In Proceedings of the 2017 International Conference on Engineering, Technology and Innovation (ICE/ITMC), Madeira, Portugal, 27-29 June 2017.

14. Christ, O.; Czarniecki, M.; Kressig, C.; Scherer, L. Satisfaction Benchmark for Smart Cities. In Happy City-How to Plan and Create the Best Livable Area for the People; EcoProduction, Environmental Issues in Logistics and Manufacturing; Brdulak, A., Brdulak, H., Eds.; Springer International Publishing: Cham, Switzerland, 2017.

15. SmartCitiesWorld. TM Forum Launches Global Smart Cities Benchmark. Available online: https://www.smartcitiesworld.net/n ews/news/tm-forum-launches-global-smart-cities-benchmark--1277 (accessed on 19 January 2020).

16. Fox, M.S. The role of ontologies in publishing and analyzing city indicators. Comput. Environ. Urban Syst. 2015, 54, 266-279. [CrossRef]

17. Fox, M.S.; Pettit, C.J. On the completeness of open city data for measuring city indicators. In Proceedings of the 2015 IEEE First International Smart Cities Conference (ISC2), Guadalajara, Mexico, 25-28 October 2015.

18. Zdraveski, V.; Mishev, K.; Trajanov, D.; Kocarev, L. ISO-Standardized Smart City Platform Architecture and Dashboard. IEEE Pervasive Comput. 2017, 16, 2. [CrossRef]

19. Founoun, A.; Hayar, A. Evaluation of the concept of the smart city through local regulation and the importance of local initiative. In Proceedings of the 2018 IEEE International Smart Cities Conference (ISC2), Kansas City, MO, USA, 16-19 September 2018.

20. Fox, M.S.; Pettit, C.J. A Transportation Ontology for Global City Indicators (ISO 37120). Technical Report. Available online: 10.13140/RG.2.2.22520.26881 (accessed on 3 March 2020).

21. ISO. ISO 37120:2014. Sustainable Development of Communities_-Indicators for City Services and Quality of Life. Available online: https:/ / www.iso.org/standard/62436.html (accessed on 1 August 2020).

22. ISO. ISO 37120:2018. Sustainable Cities and Communities-Indicators for City Services and Quality of Life. Available online: https: / / www.iso.org/standard/68498.html (accessed on 1 August 2020).

23. Berman, M.; Orttung, R.W. Measuring Progress toward Urban Sustainability: Do Global Measures Work for Arctic Cities? Sustainability 2020, 12, 3708. [CrossRef]

24. Mouyal, N. Update on the Smart City Work Taking Place in ISO/IEC JTC 1. Information Technology for Smart Cities. Available online: https: / / etech.iec.ch/issue/2020-01/information-technology-for-smart-cities (accessed on 4 March 2020).

25. Moustaka, V.; Maitis, A.; Vakali, A.; Anthopoulos, L.-G. CityDNA Dynamics: A Model for Smart City Maturity and Performance Benchmarking. In Proceedings of the Companion Proceedings of the Web Conference (WWW' 2020), Taipei, Taiwan, 20-24 April 2020.

26. WWCD. Open Data Portal. Available online: https://www.dataforcities.org (accessed on 1 September 2020).

27. ISO. ISO 37122:2019, Sustainable Cities-Indicators for Smart Cities. Available online: https://www.sis.se/api/document/prev iew / 80011945/ (accessed on 1 August 2020).

28. ISO. ISO 37123:2019, Sustainable Cities-Indicators for Resilient Cities. Available online: https://www.sis.se/api/document/pr eview/80018865/ (accessed on 1 August 2020).

29. Moustaka, V.; Vakali, A.; Anthopoulos, L.G. CityDNA: Smart City Dimensions' Correlations for Identifying Urban Profile. In Proceedings of the 26th International Conference on World Wide Web (WWW'17 Companion), Perth, Australia, 3 April 2017.

30. De Santis, R.; Fasano, A.; Mignolli, N.; Villa, V. Smart City: Fact and Fiction. Available online: https://econpapers.repec.org/pap er/pramprapa/54536.htm (accessed on 15 December 2020).

31. Kumar, H.; Singh, M.K.; Gupta, M.P.; Madaan, J. Moving towards smart cities: Solutions that lead to the Smart City Transformation Framework. Technol. Forecast. Soc. Chang. 2020, 153, 11928. [CrossRef]

32. OECD. Resilient Cities. Available online: https://www.oecd.org/regional/resilient-cities.htm\#: \{\}:text=Resilient $\% 20$ cities $\% 20 \mathrm{ar}$ e\%20cities\%20that, cities\%20can\%20increase\%20their\% (accessed on 4 March 2020).

33. Anthopoulos, L.G. Smart utopia vs smart reality: Learning by experience from 10 smart city cases. Cities 2017, 63, 128-148. [CrossRef]

34. International Telecommunications Union (ITU). Smart Sustainable Cities: An Analysis of Definitions. 2014. Available online: www.itu.int/en/ITU-T/focusgroups/ssc/Documents/Approved_Deliverables/TR-Definitions.docx (accessed on 1 August 2020). 
35. Giffinger, R.; Gudrun, H. Smart cities ranking: An effective instrument for the positioning of cities? ACE 2010, 4, 7-25.

36. Chelleri, L.; Kunath, A.; Minucci, G.; Olazabal, M.; Waters, J.J.; Yumalogava, L. Multidisciplinary perspective on urban resilience. Workshop Report. BC3, Basque Centre for Climate Change. Available online: http:/ /www.bc3research.org/multidisciplinary_pe rspectives_on_urban_resilience (accessed on 4 March 2020).

37. Papa, R.; Galderisi, A.; Vigo Majello, M.C.; Saretta, E. Smart and Resilient Cities. A Systemic Approach for Developing Cross-sectoral Strategies in the Face of Climate Change. TeMA 2015, 8, 1.

38. Wray, S. COVID-19 is shifting the focus from smart cities to resilient cities. Available online: https://cities-today.com/covid-19shifts-the-focus-from-smart-cities-to-resilient-cities / (accessed on 14 November 2020).

39. Ruiz-Mallén, I. Co-production and Resilient Cities to Climate Change. In Participatory Research and Planning in Practice; The Urban Book Series; Nared, J., Bole, D., Eds.; Springer International Publishing: Cham, Switzerland, 2020.

40. Mendizabal, M.; Heidrich, O.; Feliu, E.; García-Blanco, G.; Mendizabal, A. Stimulating urban transition and transformation to achieve sustainable and resilient cities. Renew. Sustain. Energy Rev. 2018, 94, 410-418. [CrossRef]

41. Remes, J.; Woetzel, J. Smarter Cities are Resilient Cities. Available online: https://www.mckinsey.com/industries/capital-projec ts-and-infrastructure/our-insights/smarter-cities-are-resilient-cities\# (accessed on 1 August 2020).

42. Zhu, S.; Li, D.; Feng, H.; Gu, T.; Hewage, K.; Sadiq, R. Smart city and resilient city: Differences and connections. WIREs Data Min. Knowl. Discov. 2020, 10, 6. [CrossRef]

43. Agugiaro, G.; González, F.G.G.; Cavallo, R. The City of Tomorrow from ... the Data of Today. ISPRS Int. J. Geo. Inf. 2020, 9, 554. [CrossRef]

44. Kourtit, K.; Elmlund, P.; Nijkamp, P. The urban data deluge: Challenges for smart urban planning in the third data revolution. Int. J. Urban Sci. 2020, 24, 445-461. [CrossRef]

45. Aguilera, U.; López-de-Ipiña, D.; Pérez, J. Collaboration-Centred Cities through Urban Apps Based on Open and User-Generated Data. Sensors 2016, 16, 1022. [CrossRef]

46. Ottenburger, S.; Airaksinen, M.; Pinto-Seppa, I.; Raskob, W. Enhancing urban resilience via a real-time decision support system for smart cities. In Proceedings of the 2017 International Conference on Engineering, Technology and Innovation (ICE/ITMC), Madeira, Portugal, 27-29 June 2020.

47. Frost and Sullivan. Smart Cities. Available online: https://ww2.frost.com/wp-content/uploads/2019/01/SmartCities.pdf (accessed on 4 March 2020).

48. Misra, A.; Gooze, A.; Watkins, K.; Asad, M.; Le Dantec, C.-A. Crowdsourcing and Its Application to Transportation Data Collection and Management. Transp. Res. Rec. J. Transp. Res. Board 2014, 2414, 1-8. [CrossRef]

49. Talari, S.; Shafie-khah, M.; Siano, P.; Loia, V.; Tommasetti, A.; Catalão, J. A Review of Smart Cities Based on the Internet of Things Concept. Energies 2017, 10, 421. [CrossRef]

50. Miranda, J.; Mäkitalo, N.; Garcia-Alonso, J.; Berrocal, J.; Mikkonen, T.; Canal, C.; Murilloand, J.M. From the internet of things to the internet of people. IEEE Internet Comput. 2015, 19, 40-47. [CrossRef]

51. Levina, O.; Kranich, L. Mobility and the Internet of People: A Morphological Analysis. In Proceedings of the 2016 Intl IEEE Conferences on Ubiquitous Intelligence \& Computing, Advanced and Trusted Computing, Scalable Computing and Communications, Cloud and Big Data Computing, Internet of People, and Smart World Congress (UIC/ATC/ScalCom/CBDCom/IoP/SmartWorld), Toulouse, France, 18-21 July 2016.

52. Guillén, J.; Miranda, J.; Berrocal, J.; García-Alonso, J.; Murillo, J.M.; Canal, C. People as a Service: A Mobile-centric Model for Providing Collective Sociological Profiles. IEEE Softw. 2014, 31, 48-53. [CrossRef]

53. Vakali, A.; Moustaka, V. City dynamics tracking based on citizens data and sensing analytics. In Smart Cities in the Post-Algorithmic Era: Integrating Technologies, Platforms and Governance; Komninos, N., Kakderi, C., Eds.; Edward Elgar Publishing: Northampton, MA, USA, 2019.

54. Estellés-Arolas, E.; González Ladrónâ de Guevara, F. Towards an integrated crowdsourcing definition. J. Inf. Sci. 2012, 38, 1-14. [CrossRef]

55. Guo, B.; Wang, Z.; Yu, Z.; Wang, Y.; Yen, N.-Y.; Huang, R.; Zhou, X. Mobile crowd sensing and computing: The review of an emerging human-powered sensing paradigm. ACM Comp. Surv. 2015, 48, 1. [CrossRef]

56. Srivastava, P.; Mostafavi, A. Challenges and Opportunities of Crowdsourcing and Participatory Planning in Developing Infrastructure Systems of Smart Cities. Infrastructures 2018, 3, 51. [CrossRef]

57. Laubis, K.; Simko, V.; Schuller, A. Crowd sensing of road conditions and its monetary implications on vehicle navigation. In Proceedings of the 2016 Intl IEEE Conferences on Ubiquitous Intelligence \& Computing, Advanced and Trusted Computing, Scalable Computing and Communications, Cloud and Big Data Computing, Internet of People, and Smart World Congress (UIC/ATC/ScalCom/CBDCom/IoP/SmartWorld), Toulouse, France, 18-21 July 2016.

58. Fernandez-Ares, A.; Mora, A.M.; Arenas, M.G.; Garcia-Sanchez, P.; Romero, G.; Rivas, V.; Castillo, P.A.; Merelo, J.J. Studying real traffic and mobility scenarios for a smart city using a new monitoring and tracking system. Future Gener. Comput. Syst. 2017, 76, 163-179. [CrossRef]

59. Wan, X.; Ghazzai, H.; Massoud, Y. Mobile Crowdsourcing for Intelligent Transportation Systems: Real-Time Navigation in Urban Areas. IEEE Access 2019, 7, 136995-137009. [CrossRef] 
60. Wang, L.; Yang, C.; Yu, Z.; Liu, Y.; Wang, Z.; Guo, B. CrackSense: A CrowdSourcing Based Urban Road Crack Detection System. In Proceedings of the 2019 IEEE SmartWorld, Ubiquitous Intelligence \& Computing, Advanced \& Trusted Computing, Scalable Computing \& Communications, Cloud \& Big Data Computing, Internet of People and Smart City Innovation (SmartWorld/SCALCOM/UIC/ATC/CBDCom/IOP/SCI), Leicester, UK, 19-23 August 2019.

61. Glaeser, E.L.; Kominers, S.D.; Luca, M.; Naik, N. Big Data and Big Cities: The Promises and Limitations of Improved Measures of Urban Life. Econ. Inq. 2018, 56, 1. [CrossRef]

62. Kong, X.; Liu, X.; Jedari, B.; Li, M.; Wan, L.; Xia, F. Mobile Crowdsourcing in Smart Cities: Technologies, Applications, and Future Challenges. IEEE Internet Things J. 2019, 6, 8095-8113. [CrossRef]

63. Alizadeh, T. Crowdsourced Smart Cities versus Corporate Smart Cities. IOP Conf. Ser. Earth Environ. Sci. 2018, 158, 012046. [CrossRef]

64. Thorsby, J.; Stowers, G.N.L.; Wolslegel, K.; Tumbuan, E. Understanding the content and features of open data portals in American cities. Gov. Inf. Q. 2017, 34, 53-61. [CrossRef]

65. Badidi, E.; Maheswaran, M. Towards a Platform for Urban Data Management, Integration and Processing. In Proceedings of the 3rd International Conference on Internet of Things, Big Data and Security (IoTBDS 2018), Funchal, Portugal, 19-21 March 2018.

66. City Resilience Index. Inside the CRI: A Reference Guide; Research Report: Measurement Guide; Arup and The Rockefeller Foundation: London, UK, 2016; Volume 6, Available online: www.cityresilienceindex.org (accessed on 4 March 2020).

67. Science for Environment Policy, Indicators for Sustainable Cities; In-depth Report 12; Produced for the European Commission DG Environment. Science Communication Unit, UWE: Bristol, UK, 2018. Available online: http:/ / ec.europa.eu/science-environme nt-policy (accessed on 12 November 2020).

68. Petrova-Antonova, D.; Ilieva, S. Smart Cities Evaluation-A Survey of Performance and Sustainability Indicators. In Proceedings of the 44th Euromicro Conference on Software Engineering and Advanced Applications (SEAA), Prague, Czech Republic, 29-31 August 2018.

69. Figueiredo, L.; Honiden, T.; Schumann, A. Indicators for Resilient Cities; OECD Regional Development Working Papers; OECD Publishing: Paris, France, 2018; Volume 2018/02. [CrossRef]

70. Ma, Y.; Li, G.; Xie, H.; Zhang, H. City profile: Using smart data to create digital urban spaces. ISPRS Ann. Photogramm. Remote. Sens. Spat. Inf. Sci. 2018, V-4/W7, 75-82. [CrossRef]

71. URBACT. The Profile of the City. Available online: https://urbact.eu/profile-city (accessed on 2 August 2020).

72. Shen, L.; Huang, Z.; Wong, S.W.; Liao, S.; Lou, Y. A holistic evaluation of smart city performance in the context of China. J. Clean. Prod. 2018, 200, 667-679. [CrossRef]

73. Picioroaga, I.-I.; Eremia, M.; Sanduleac, M. SMART CITY: Definition and Evaluation of Key Performance Indicators. In Proceedings of the 2018 International Conference and Exposition on Electrical and Power Engineering (EPE), Iaşi, Romania, 19-21 October 2018.

74. Lima, E.G.; Chinelli, C.K.; Guedes, A.L.A.; Vazquez, E.G.; Hammad, A.W.A.; Haddad, A.N.; Soares, C.A.P. Smart and Sustainable Cities: The Main Guidelines of City Statute for Increasing the Intelligence of Brazilian Cities. Sustainability 2020, $12,1025$. [CrossRef]

75. ISO. ISO and Sustainable Cities. Available online: https://www.iso.org/files/live/sites/isoorg/files/store/en/PUB100423.pdf (accessed on 2 August 2020).

76. Chang, H.-T. Green City Vision, Strategy, and Planning. In Green City Planning and Practices in Asian Cities: Sustainable Development and Smart Growth in Urban Environments; Shen, Z., Huang, L., Peng, K., Pai, J., Eds.; Springer International Publishing: Cham, Switzerland, 2018.

77. International Telecommunications Union (ITU). A Guide to Circular Cities. 2020. Available online: https://www.itu.int/en/myi tu/Publications/2020/06/25/16/22/Guide-to-Circular-Cities (accessed on 10 July 2021).

78. World Health Organization (WHO). What is a Healthy City? Available online: https://www.euro.who.int/en/health-topics/en vironment-and-health/urban-health/who-european-healthy-cities-network/what-is-a-healthy-city (accessed on 10 July 2021).

79. U.S. National Library of Medicine. What Is DNA? Available online: https://ghr.nlm.nih.gov/primer/basics/dna (accessed on 19 January 2020).

80. Merriam-Webster. Organic. Available online: https://www.merriam-webster.com/dictionary/organic (accessed on 15 December 2020).

81. CyberBridge. Nucleotides and the Double Helix. Available online: http://cyberbridge.mcb.harvard.edu/dna_1.html (accessed on 19 January 2020).

82. Douglas Lenat, B. The nature of heuristics. Artif. Intell. 1982, 19, 2.

83. Lechler, A. Open Architecture. The International Academy for Production Engineering. In CIRP Encyclopedia of Production Engineering; Laperrière, L., Reinhart, G., Eds.; Springer: Berlin/Heidelberg, Germany, 2014.

84. IESE. Resilience, a Key Concept for the World's Smartest Cities. Available online: https://www.ieseinsight.com/doc.aspx?id=23 28\&ar=15\&idi=2\&idioma=2_blank (accessed on 4 August 2020).

85. The Guardian. Inside Greece's First Smart City: Now You Don't Need to Know a Politician to Get Something Done. Available online: https: / / www.theguardian.com/cities / 2018/sep/04/trikala-greece-first-smart-city-dont-need-to-know-a-politician-t o-getsomething-done (accessed on 9 September 2020). 
86. British Standards Institute (BSI). Mapping Smart City Standards: Based on a Data Flow Model. Available online: https: / / www.bsigroup.com/en-GB/smart-cities/smart-cities-standards-mapping-research-and-modelling/ (accessed on 10 July 2021).

87. Pan, Y.; Tian, Y.; Liu, X.; Gu, D.; Hua, G. Urban Big Data and the Development of City Intelligence. Engineering 2016, 2, 171-178. [CrossRef]

88. EU GDPR Portal. GDPR Key Changes. Available online: https://www.eugdpr.org/theregulation.html (accessed on 4 March 2020). 